This item was submitted to Loughborough's Research Repository by the author.

Items in Figshare are protected by copyright, with all rights reserved, unless otherwise indicated.

\title{
Microencapsulation of oil droplets using cold water fish gelatine/gum arabic complex coacervation by membrane emulsification
}

PLEASE CITE THE PUBLISHED VERSION

http://dx.doi.org/10.1016/j.foodres.2013.04.012

\section{PUBLISHER}

(C) Elsevier

VERSION

AM (Accepted Manuscript)

\section{PUBLISHER STATEMENT}

This work is made available according to the conditions of the Creative Commons Attribution-NonCommercialNoDerivatives 4.0 International (CC BY-NC-ND 4.0) licence. Full details of this licence are available at: https://creativecommons.org/licenses/by-nc-nd/4.0/

\section{LICENCE}

CC BY-NC-ND 4.0

\section{REPOSITORY RECORD}

Piacentini, Emma, L. Giorno, Marijana M. Dragosavac, Goran T. Vladisavljevic, and R.G. Holdich. 2015. "Microencapsulation of Oil Droplets Using Cold Water Fish Gelatine/gum Arabic Complex Coacervation by Membrane Emulsification". figshare. https://hdl.handle.net/2134/18699. 


\section{Accepted Manuscript}

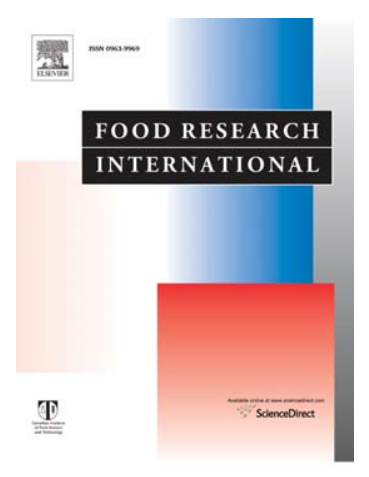

PII: $\quad$ S0963-9969(13)00240-8

Microencapsulation of oil droplets using cold water fish gelatine/gum arabic complex coacervation by membrane emulsification

Emma Piacentini, Lidietta Giorno, Marijana M. Dragosavac, Goran T. Vladisavljević, Richard G. Holdich

DOI: $\quad$ doi: $10.1016 /$ j.foodres.2013.04.012

Reference: $\quad$ FRIN 4614

To appear in: $\quad$ Food Research International

Received date: 17 January 2013

Accepted date: 19 April 2013

Please cite this article as: Piacentini, E., Giorno, L., Dragosavac, M.M., Vladisavljević, G.T. \& Holdich, R.G., Microencapsulation of oil droplets using cold water fish gelatine/gum arabic complex coacervation by membrane emulsification, Food Research International (2013), doi: 10.1016/j.foodres.2013.04.012

This is a PDF file of an unedited manuscript that has been accepted for publication. As a service to our customers we are providing this early version of the manuscript. The manuscript will undergo copyediting, typesetting, and review of the resulting proof before it is published in its final form. Please note that during the production process errors may be discovered which could affect the content, and all legal disclaimers that apply to the journal pertain. 


\title{
Microencapsulation of oil droplets using cold water fish gelatine/gum arabic complex coacervation by membrane emulsification
}

\author{
Emma Piacentini ${ }^{\mathrm{a}}$, Lidietta Giorno ${ }^{\mathrm{a}}$, Marijana M. Dragosavac ${ }^{\mathrm{b}^{*}}$, Goran T. Vladisavljević ${ }^{\mathrm{b}}$ \\ and Richard G. Holdich ${ }^{\mathrm{b}}$
}

\begin{abstract}
${ }^{a}$ Institute on Membrane Technology, National Research Council, ITM-CNR, Via P. Bucci 17/C at University of Calabria, 87036 Rende (CS), Italy

${ }^{\mathrm{b}}$ Department of Chemical Engineering, Loughborough University, Leicestershire, LE11 3TU, U.K.
\end{abstract}

*Coressponding author at: Chemical Engineering Department, Loughborough University, Loughborough, Leicestershire LE11 3TU, UK. Tel.: +44 01509222 501; fax: +44 01509223923.

E-mail address: m.dragosavac@lboro.ac.uk

\begin{abstract}
Food grade sunflower oil was microencapsulated using cold water fish gelatine (FG) - gum arabic (GA) complex coacervation in combination with a batch stirred cell or continuous pulsed flow membrane emulsification system. Oil droplets with a controllable median size of $40-240 \mu \mathrm{m}$ and a particle span as low as 0.46 were generated using a microengineered membrane with a pore size of $10 \mu \mathrm{m}$ and a pore spacing of $200 \mu \mathrm{m}$ at the shear stress of $1.3-$ $24 \mathrm{~Pa}$. A biopolymer shell around the oil droplets was formed under room temperature conditions at $\mathrm{pH} 2.7-4.5$ and a total biopolymer concentration lower than $4 \% \mathrm{w} / \mathrm{w}$ using weight ratios of FG to GA from 40:60 to 80:20. The maximum coacervate yield was achieved at $\mathrm{pH} 3.5$ and a weight ratio of FG to GA of 50:50. The liquid biopolymer coating around the droplets was crosslinked with glutaraldehyde (GTA) to form a solid shell. A minimum concentration of GTA of $1.4 \mathrm{M}$ was necessary to promote the crosslinking reaction between FG and GTA and the optimal GTA concentration was $24 \mathrm{M}$. The developed method allows a continuous production of complex coacervate microcapsules of controlled size, under mild shear stress conditions, using considerably less energy when compared to alternative gelatine types and production methods.
\end{abstract}


Keywords: Membrane emulsification; Complex coacervation; Microcapsules; Oil encapsulation; Fish gelatine; Gum arabic.

\section{Introduction}

Microencapsulation is a technique by which material is coated or entrapped within another one which forms a protective shell or wall (Burgess \& Ponsart, 1998; Madene et al., 2006). Usually it is performed in order to isolate and protect the material from the environment or to promote the controlled release (Benita, 2005). Complex coacervation is a spontaneous phenomenon that occurs between two oppositely charged polymers and the neutralization of these charges induces a phase separation (polymer rich phase vs. aqueous phase), which has been applied extensively in microencapsulation (Bungenberg de Jong H., 1949; Schmitt et al., 1998; de Kruif et al., 2004; Turgeon et al., 2007) Although spontaneous, this phenomenon occurs only under very specific conditions which will depend on the charge of the polymers, their charge density, the surface tension in the system, the temperature at which the system is maintained and the dynamics of the system (stirring and cooling) ( Leclercq et al., 2008)

Typical steps in microencapsulation of hydrophobic material by complex coacervation process involve: i) emulsification of hydrophobic material (oil) in an aqueous solution containing two different polymers (most commonly a protein and a polysaccharide), usually at a temperature above the gelling point of protein and $\mathrm{pH}$ that is above the isoelectric point of protein; ii) separation into two liquid phases (an insoluble polymer rich phase and an aqueous phase that is depleted in both polymers) as a result of attractive electrostatic interactions between oppositely charged polymers caused by lowering the solution $\mathrm{pH}$ below the isoelectric point of protein; iii) wall formation due to deposition of the polymer rich phase around the droplets of the hydrophobic material - induced by controlled cooling below the gelling temperature; iv) wall hardening by addition of a crosslinking agent in order to obtain hard microcapsules. The most classical example of complex coacervation is the gelatine/gum arabic (GE/GA) system in which GE and GA are used as positive and negative polyelectrolyte, respectively (Lemetter et al., 2009). The system has been successfully used for different applications such as the production of carbonless paper (Green \& Schleicher, 1956), the encapsulation of flavour compounds (Leclercq et al., 2008; Soper, 1997; Wampler, et al., 1998; Yeo et al., 2005) and lipophilic drugs (Jizomoto et al., 1993; Junyaprasert et al., 2001). Gelatin can be obtained from pig skin, bovine hide, pork and cattle bones, and marine 
sources (warm- and cold-water fish skins, bones and fins). Worldwide religious sentiments, vegetarian nutritional requirements, the risk associated with the transmission of pathogenic vectors such as Bovine Spongiform Encephalopathy prions by tissue-derived collagens and gelatines has led to alternatives to mammalian gelatine. In these regards, gelatine obtained from marine sources has received increased interest in recent years (Karim \& Bhat, 2009, Surh et al., 2006).

The use of fish gelatine (FG), as an alternative to mammalian gelatine, can bring various advantages in complex coacervation processes. The gelling point of $\mathrm{FG}\left(8-25^{\circ} \mathrm{C}\right.$ and $11-28^{\circ} \mathrm{C}$ for cold- and warm-water fish gelatine, respectively) enables a process at about ambient or slightly above-ambient temperatures that allows i) to reduce the duration of the heating step shortening the overall processing time, ii) to prevent the loss of volatile encapsulantes such as flavours and fragrances, iii) to preserve the bioactivity of heat sensitive components such as drugs or biomolecules. Warm water FG having a gelling temperature of $27^{\circ} \mathrm{C}$ and gum arabic (GA) were used to prepare microcapsules by complex coacervation (Soper, 1997; G. Dardelle, 2012). The process was carried out at $27^{\circ} \mathrm{C}$ and the mixture was cooled down to $20^{\circ} \mathrm{C}$. The interaction occurring between cold water FG and GA molecules in aqueous solutions has been investigated (Yang et al., 2012). Quan et al. (2012) reported the use of FG for the production of microcapsules with a solid lipid core. The melted lipid droplets were initially produced by sonication, but the resulting microcapsules had a wide size distribution.

The design of microcapsules with tailor-made properties in terms of composition, size and size distribution and the development of mild (minimal shear) encapsulation techniques is still an important challenge in microencapsulation technology. In recent years membrane emulsification has been explored as an advanced encapsulation technique that allows the production of uniform particles of controlled size. It is a dispersion process to produce droplets of one liquid phase (e.g. oil) in a second immiscible liquid phase (e.g. water) by injecting the dispersed phase through the membrane using low energy per unit volume. The droplet size is mainly influenced by the pore size and the shear stress applied on the membrane surface (Vladisavljević \& Williams, 2005). Conventional emulsification devices (high pressure homogenisers, ultrasonic processors, rotor-stator systems) are not suitable for use when dealing with shear sensitive substances, because they apply more energy than needed for the disruption of droplets and the energy input within the device is not uniform, leading to the droplets with a wide size distribution. Membrane emulsification has been used to produce polymeric microspheres and microcapsules (Chu et al., 2002; Wei et al., 2008; 
Gasparini et al., 2008), solid lipid microcapsules (Kukizaki \& Goto 2007), and agarose microbeads (Zhou et al., 2007) but microencapsulation of oil droplets produced by membrane emulsification has not yet been demonstrated using complex coacervation. A microchannel emulsification system has been used to prepare gelatine/acacia coacervate microcapsules (Nakagawa et al., 2004). However microchannel emulsification, due to the low volume flow rate of the dispersed phase, is mainly applied at the small batch scale for niche production and laboratory research.

The paper reports the use of membrane emulsification for production of uniform microcapsules with diameters between 40 and $270 \mu \mathrm{m}$ having a single liquid oil core using cold water fish gelatine and gum arabic. The influence of operating parameters, $\mathrm{pH}$, biopolymer ratio, total biopolymer concentration, presence of surfactant, and dispersed phase concentration on the production of microcapsules was investigated in a Dispersion Cell (Stillwell et al., 2008). For scaling up of the process the conventional cross-flow membrane emulsification, where the shear is induced by recycled flow of the continuous phase, is not convenient for the production of droplets larger than $20 \mu \mathrm{m}$, due to break up in the pump. Therefore the continuous membrane emulsification with pulsed (oscillatory) flow (Holdich et al., 2013) was investigated.

\section{Methods and Materials}

\subsection{Experimental}

Commercially available food grade sunflower oil was used without further purification. Fish gelatine from cold water fish skin, gum arabic from Acacia tree, lactic acid and 50\% w/w glutaraldehyde were purchased from Sigma-Aldrich, UK.

In all the experiments mixtures of FG and GA were used as a continuous phase. Separate stock solutions of FG $(10 \% \mathrm{w} / \mathrm{w})$ and GA $(10 \% \mathrm{w} / \mathrm{w})$ were prepared by dispersing the weighed amounts of FG and GA in distilled water. The solutions were gently stirred and incubated at $40^{\circ} \mathrm{C}$ for $1 \mathrm{~h}$ and were left to cool down to room temperature. Aqueous biopolymer mixtures were prepared by mixing and diluting the stock solutions of FG and GA with distilled water. 
During the formulation stage, which included finding the optimum $\mathrm{pH}$, biopolymer ratio and concentration, emulsions were produced using a Dispersion Cell (Stillwell, 2005; Gasparini, 2008; Dragosavac, 2008) fitted with a flat disc hydrophilic nickel membrane placed under the paddle stirrer (Figure 1a). The paddle stirrer was driven by a 24 V DC motor (INSTEK Model PR 3060) and the rotation speed, controlled by the applied voltage, was varied from 170 to $1700 \mathrm{rpm}$ corresponding to shears between 0.7 and $24 \mathrm{~Pa}$ (Eq. 2). The dispersed phase was injected using a peristaltic pump (Watson-Marlow $101 \mathrm{U} / \mathrm{R}$ ). Most of the experiments were carried out at room temperature $\left(20^{\circ} \mathrm{C}\right)$. The dispersed phase (sunflower oil) was injected through the membrane into the continuous phase at a constant flow rate of $1 \mathrm{~mL}$ $\min ^{-1}$ corresponding to a dispersed phase flux of $75 \mathrm{~L} \mathrm{~m}^{-2} \mathrm{~h}^{-1}$. The volume of the aqueous biopolymer mixture in the cell (continuous phase) was $90 \mathrm{~cm}^{3}$.

Once the best formulation was determined, continuous membrane emulsification with pulsed (oscillatory) flow and tubular nickel hydrophilic membrane was used (Figure 1b). The dispersed and continuous phases were injected using peristaltic pumps (Watson-Marlow SciQ 400 Pump, Cornwall, UK). An accelerometer (PCB Piezotronics model M352C65) was connected to a National Instruments Analogue to Digital converter (NI eDAQ-9172) which was interfaced to a LabView executable program running on a PC. The information provided by the program from the accelerometer was the frequency and amplitude of the oscillation: the frequency being determined from the direction of travel, and the amplitude was deduced from the acceleration measurement. The oscillation signal to the amplifier used to drive the oscillator was provided by a National Instrument frequency generator. The power amplifier drove an electro-mechanical oscillator which was connected to a bellows designed for use in a diaphragm pump, which was submerged in the continuous phase, and its oscillation provided pulsation of the liquid. This electro-mechanic means to generate pulsed flow provided separate control of frequency and amplitude. The continuous phase oscillations with a frequency of 20 to $50 \mathrm{~Hz}$ and amplitude between 0.6 and $1.6 \mathrm{~mm}$ within the membrane tube were used, corresponding to the shears between 1.3 and $12.3 \mathrm{~Pa}$ (Eq. 6) and the influence of the dispersed phase flow rate was also investigated. The emulsion droplets produced in the membrane module were collected in a stirred tank and slowly agitated.

In both systems $10 \mu \mathrm{m}$ membranes with $200 \mu \mathrm{m}$ pore spacing and porosity of $0.2 \%$ were used. The flat disc membrane had a diameter of $33 \mathrm{~mm}$ corresponding to the effective membrane area of $8.4 \mathrm{~cm}^{2}$, whilst the tubular membrane had an internal diameter of $14 \mathrm{~mm}$ and working length of $60 \mathrm{~mm}$ and had three times bigger effective membrane area $\left(26 \mathrm{~cm}^{2}\right)$. 
Membranes, Dispersion Cell as well as continuous membrane emulsification system with pulsed (oscillatory) flow were supplied by Micropore Technologies Ltd. (Hatton, UK). After each experiment, the membranes were cleaned with commercially available soap in an ultrasonic bath for $5 \mathrm{~min}$ followed by treatment in $4 \mathrm{M} \mathrm{NaOH}$ solution for $5 \mathrm{~min}$ and finally rinsed with distilled water. Oil/water interfacial tension was measured by the Du Nouy ring method using a White Electric Instrument tensiometer (model DB2KS) and the results are reported in the Table 1.

\subsection{Microencapsulation}

The emulsions produced at the original $\mathrm{pH}$ of the biopolymer mixture $(5.4 \pm 0.2)$ were transferred into a beaker with controlled overhead stirring where complex coacervation was initiated by adjusting the $\mathrm{pH}$ with $56 \% \mathrm{w} / \mathrm{w}$ lactic acid. During the shell formation stage the mixture was stirred to prevent droplets from sticking to each other. Microcapsules obtained by complex coacervation were then crosslinked with glutaraldehyde and left stirring until solidified. According to Quan et al. (2012), cooling to $4^{\circ} \mathrm{C}$ promotes coacervation and gelatine crosslinking. In this work, however, no improvement in shell formation and shell stability was observed by cooling and therefore, the crosslinking was done at room temperature. During the formulation stage the influence of the total biopolymer concentration, biopolymer ratio, $\mathrm{pH}$, temperature, stirring speed as well as the amount of the crosslinking agent was investigated. After solidification the capsules were washed with warm water $\left(50^{\circ} \mathrm{C}\right)$ to confirm that the shell around them was robust. Each experiment was run at least in triplicate and average values are reported where appropriate. The error bars indicate the lowest and the highest value obtained in the experiments.

\subsection{Particle size analysis}

The droplet/particle size distribution and droplet/particle diameter were analysed using a laser diffraction particle size analyser (Malvern Mastersizer, Model S). For each emulsion, three separate samples and measurements were performed and the mean average of these is reported. The mean particle diameter is expressed as the volume median diameter $D(V, 0.5)$, which is the diameter corresponding to $50 \% \mathrm{v} / \mathrm{v}$ on the cumulative distribution curve. The relative span of a particle size distribution $(\operatorname{span}=(D(V, 0.9)-D(V, 0.1)) / D(V, 0.5))$ was 
used to express the degree of uniformity. Photomicrographs of the prepared emulsions were also taken using a Leitz Ergolux optical microscope. Position of the oil within the capsule was evaluated using a confocal laser scanning microscope (Biorad Laser Scanning Confocal Imaging System equipped with argon laser system and Zeiss inverted microscope). For those experiments Nile Red was dissolved in the oil phase and for detection an excitation wavelength at $488 \mathrm{~nm}$ was used while the emission wave length was $550 \mathrm{~nm}$.

\subsection{Modelling of the droplet size}

To predict the droplet size in a Dispersion Cell a model introduced in previous work for simple emulsions (Kosvintsev et al, 2005) was used. The droplet diameter $x$ is calculated from a force balance of the capillary force (function of interfacial tension and pore size) and the drag force (function of a shear stress and the droplet size) acting on a strongly deformed droplet at a single membrane pore:

$$
x=\frac{\sqrt{18 \tau^{2} r_{p}^{2}+2 \sqrt{81 \tau^{4} r_{p}^{4}+4 r_{p}^{2} \tau^{2} \gamma^{2}}}}{3 \tau}
$$

where $r_{p}$ is the pore radius, $\tau$ is the maximal shear stress, $\gamma$ is the interfacial tension and $x$ is the formed droplet diameter. The maximal shear over the whole membrane area is given by:

$$
\tau=0.825 \eta \omega r_{\text {trans }} \frac{1}{\delta}
$$

where $r_{\text {trans }}$ is the transitional radius (Kosvintsev et al., 2005), $\eta$ is the dynamic viscosity of continuous phase, $\rho$ is the continuous phase density, $\omega$ is the angular velocity, and $\delta$ is the boundary layer thickness, $\delta=\sqrt{\mu / \omega \rho}$.

In the case of continuous membrane emulsification with pulsed (oscillatory) flow if the occurrence of turbulence and bursts near the membrane surface can be neglected, then it may be possible to correlate droplet size with the shear stress at the membrane surface based on the wave equation for shear stress (Holdich et al., 2013):

$$
\tau=v_{o}\left(\frac{\omega_{f} \mu \rho}{2}\right)^{1 / 2}\left[\sin \left(\omega_{f} t\right)-\cos \left(\omega_{f} t\right)\right]
$$


where $\omega_{f}$ is the angular frequency, determined by:

$$
\omega_{f}=2 \pi f
$$

where $f$ is the frequency of the oscillation and $v_{\mathrm{o}}$ is the peak velocity related to both the angular frequency and the amplitude $(a)$ of oscillation by the equation:

$$
v_{o}=\omega_{f} a
$$

A peak shear event occurs when the value of wall shear provided by equation (3) is at a maximum:

$$
\tau_{\max }=\omega_{f}^{3 / 2} a(\mu \rho / 2)^{1 / 2}=2 a(\pi f)^{3 / 2}(\mu \rho)^{1 / 2}
$$

The maximum shear occurs twice per cycle, and it is the maximum shear that is used in equation (1) to determine droplet size.

\section{Results and Discussion}

\subsection{Effect of the weight ratio of FG to GA in the aqueous biopolymer mixtures}

Most authors suggest an initial emulsification stage with gelatine (pig gelatine (Nakagawa et al., 2004; Yeo et al., 2005) or fish gelatine (Quan et al., 2012) followed by addition of gum arabic. In the Dispersion Cell emulsification was tested using $1 \%$ w/w FG, $1 \%$ w/w GA or a mixed solution of $1 \% \mathrm{w} / \mathrm{w} \mathrm{FG}$ and $1 \% \mathrm{w} / \mathrm{w}$ GA as a continuous phase, and the results are reported in Figure 2. The emulsions with the biggest droplet size $(298 \mu \mathrm{m})$ were obtained when $1 \%$ w/w GA was used as the continuous phase. More than three times smaller sizes of droplets $(91 \mu \mathrm{m})$ were obtained when $1 \% \mathrm{w} / \mathrm{w}$ FG or polymer blend (1\% w/w FG and 1\% w/w GA) was used for stabilising the droplets. A $1 \%$ w/w GA solution has a greater interfacial tension than the $1 \% \mathrm{w} / \mathrm{w}$ FG (Table 1) and a greater interfacial tension will provide larger droplets, as indicated by equation (1). In addition, GA is a bigger molecule (382 $\mathrm{kDa})$ compared to the FG molecule $(58 \mathrm{kDa})$ meaning that the GA molecule would diffuse slower to stabilise the droplets which would then grow longer on the membrane surface (Schröder et al., 1998). The most uniform droplets with a span of 0.56 were produced using a mixed biopolymer solution. FG and GA had a synergistic effect on emulsion stabilization and they contributed together to form an interfacial membrane at the oil-water 
interface. The biopolymer solution containing FG and GA had a different functional characteristic from either of the individual components, confirmed by the measurement of the interfacial and surface tension (Table 1). Attractive interactions between FG and GA exist even when both polymers are negatively charged (at pH 5.5) (Yang et al., 2012) and possibly when combined together they stabilise the droplets more effectively than when separately used. Therefore, it was decided that FG and GA were mixed at various ratios and used as a continuous phase during the emulsification step. To estimate the influence of FG to GA ratio (FG:GA) in the aqueous biopolymer mixture on the median particle size and particle size distribution, FG:GA was varied from 30:70 to 80:20 at a fixed total biopolymer concentration $\left(\mathrm{BP}_{\text {Тот }}\right)$ of $2 \% \mathrm{w} / \mathrm{w}$. Particle size, size distribution and interfacial tension appeared not to be significantly influenced by the FG:GA ratio in the aqueous biopolymer mixtures (Figure 3). The median particle diameter and span for the given range of FG:GA used were $(89 \pm 3) \mu \mathrm{m}$ and $0.5 \pm 0.04$, respectively. The interfacial tension at the oil-water interface was in the range between 12.2 and $12.4 \mathrm{mN} \mathrm{m}^{-1}$ when the FG:GA was varied from 30:70 to 70:30 at a fixed total biopolymer concentration $\left(\mathrm{BP}_{\mathrm{TOT}}\right)$ of $2 \% \mathrm{w} / \mathrm{w}$ and a $\mathrm{pH}$ of $5.4 \pm 0.2$, and the solutions were clear confirming that coacervation was not occurring.

Once the droplets were emulsified in the biopolymer mixture, the $\mathrm{pH}$ was altered to promote complex coacervation and deposition of the coacervate phase around the oil droplets. The complex coacervation reaction is a function of the FG to GA ratio in the aqueous phase and for a given FG:GA there exists a $\mathrm{pH}$ value at which the coacervates yield the highest turbidity (Yang et al., 2012). The coacervation between FG and GA can occur only if the $\mathrm{pH}$ value of the solution is lower than the isoelectric point of FG (4.81) and the attraction between oppositely charged FG and GA molecules cause the formation of a (FG -GA)-rich phase around oil droplets. If the electrostatic attraction between FG and GA molecules was not strong enough to promote phase separation, the formation of a shell around oil droplets was not observed. Table 1 reports the $\mathrm{pH}$ that corresponds to the maximum reaction intensity at a given FG:GA ratio. Figure 4 illustrates the microscope images of complex coacervate microcapsules produced using different ratios of FG to GA. The capsules presented in Figure 4 were crosslinked, washed with hot water and redispersed in water to confirm the presence of solid shell. The formation of complex coacervates was not observed at a FG:GA of 30:70 (Figure 4 a) while the maximum complex coacervation yield corresponded to $\mathrm{pH} 3.5$ and FG:GA $=50: 50$ (Figure 4 d). A FG:GA of 50:50 corresponds to a FG to GA molar ratio of 6.6, meaning that around 7 FG molecules were complexed with one GA molecule (Yang et 
al., 2012). The formation of a (FG-GA)-rich phase around oil droplets was also possible at higher and lower FG to GA ratio (40:60 and 80:20) but the reaction was slower and the shell around the oil droplets appeared to be thinner (Figure 4 b, c).

\subsection{Effect of total biopolymer concentration}

The size of oil droplets formed during membrane emulsification decreased with increasing the total biopolymer concentration $\left(\mathrm{BP}_{\mathrm{TOT}}\right)$ in the aqueous phase from 0.5 to $4 \% \mathrm{w} / \mathrm{w}$ at FG:GA $=50: 50$ (Figure 5). The droplets were more uniform as $\mathrm{BP}_{\mathrm{TOT}}$ increased, which could be attributed to a higher number of biopolymer molecules which were able to completely cover the entire surface of the droplets created at the membrane pore/water interface preventing droplet coalescence that could occurred immediately after emulsion production. The increase of $\mathrm{BP}_{\text {Tот }}$ decreased the interfacial tension (Table 1) causing a decrease in the droplet size, according to Eq. 1.

The total biopolymer concentration $\left(\mathrm{BP}_{\text {TOT }}\right)$ significantly affected the complex coacervation reaction and shell formation around the droplets. After $\mathrm{pH}$ adjustment the formation of the shell around the oil droplets was not observed when $\mathrm{BP}_{\text {тот }}$ was $4 \%$ w/w no matter the $\mathrm{pH}$ and similar behavior was observed by Yang et al. (2012). The magnitude and the range of the electrostatic attraction/repulsion between oppositely charged biopolymers are influenced by the electrostatic screening due to the accumulation of ions around polyelectrolyte surfaces. Higher concentration of biopolymers means more charged sites available to interact, thus more complex formed, but at the same time more counter ions released in the solution. The ions released in the solution decrease the Debye length and reduce the ability of the oppositely charged polypeptides to interact (Weinbreck et al., 2003, Priftis \& Tirrell, 2012).

\subsection{Effect of sodium dodecyl sulphate}

Previous studies showed that the presence of anionic surfactants in the aqueous phase could increase the coacervation yield. Mayya et al. (2003) achieved a higher yield of complex coacervates when the SDS concentration increased from 0.005 to $0.24 \% \mathrm{w} / \mathrm{w}$. Several authors (Mayya et al., 2003; Bhattacharyya \& Argillier, 2005) have suggested a model for the formation of the capsule wall assuming that first a primary layer of surface active 
polyelectrolyte-ionic surfactant complex is formed around the oil droplets, followed by a secondary layer of the conjugate polyelectrolyte-polyelectrolyte complex. They claimed that the presence of surfactant improved the wettability of the coacervate. In the tests performed here $0.01 \% \mathrm{w} / \mathrm{w}$ sodium dodecyl sulphate (SDS) (less than its critical micelle concentration of $0.24 \% \mathrm{w} / \mathrm{w})$ was added to the 50:50 FG:GA $\left(\mathrm{BP}_{\mathrm{TOT}}=2 \% \mathrm{w} / \mathrm{w}\right)$ solution during the emulsification stage. Figure 6 shows the influence of SDS on the particle size and particle size distribution. The average particle size decreased in the presence of SDS, which could be contributed to a decrease in the interfacial tension to about half of the value measured in the absence of SDS (Table 1). This indicates the formation of a complex between SDS and biopolymers with a strong surface activity that was able to adsorb fast at the expanding oil/water interface providing a decrease in particle size. The presence of SDS did not change the uniformity of the particles therefore the addition of the surfactant to the solution could be beneficial if smaller droplets/particles are required.

\subsection{Influence of crosslinking agent and stirring speed during solidification stage on microcapsule formation}

Since gelatine is soluble in an aqueous solution, gelatine based materials including complex coacervates for long-term applications must be subjected to crosslinking, which improves both the thermal and the mechanical stability of the material. Physical crosslinking methods include dehydrothermal treatment and ultraviolet and gamma irradiation. Due to the large number of functional side groups it contains, gelatine readily undergoes chemical crosslinking (Alvim and Grosso, 2010). Gelatine contains approximately $16 \varepsilon$-amino groups and approximately 60 carboxylic acid groups on an ideal 50,000 Da molecule composed of 500 amino acid residues. Thus, the zero spacer arm crosslink bridge has the potential to form a highly crosslinked matrix (Veis, 1964). Glutaraldehyde (GTA) is a well-known chemical crosslinking agent. Crosslinking occurs through the chemical coupling of the aldehyde groups with the free amino groups of the gelatine (Hermanson 1996). This type of crosslinking is irreversible and resistant to extreme conditions of $\mathrm{pH}$ and temperature (Migneault et al. 2004). The reaction of GE/GA complex coacervates with GTA was studied at the constant values of FG:GA of 50:50 and $\mathrm{BP}_{\mathrm{TOT}}$ of $2 \% \mathrm{w} / \mathrm{w}$, which proved to yield the thickest shell around the particles (Figure 4). 
Once oil was injected through the membrane into the continuous phase (a 50:50 mixture of FG and GA), the $\mathrm{pH}$ was adjusted to 3.5 by adding lactic acid under stirring. Shell formation was tracked under the microscope and can be seen in the Figure 7. The concentration of GTA was varied from 0.24 to $47.6 \mathrm{M}$ corresponding to GTA/FG ratio between 0.02 and 2.3 while the stirring speed was kept constant at $370 \mathrm{rpm}$ and the reaction was stirred overnight. When the concentration of GTA was below $1 \mathrm{M}$, the microcapsules were not crosslinked and a sticky (unsolidified) shell was obtained around the particles. In this case, when the stirring speed was stopped the particles aggregated into soft clusters and were not able to survive washing with hot water, meaning that there were not enough molecules of GTA to crosslink the gelatine. Lowering the temperature, which is usually used during the coacervation to increase the solidification (Quan et al., 2012; Leclercq et al., 2008), did not help in forming the solid shell. Too high concentration of GTA, greater than $24 \mathrm{M}$ corresponding to GTA/FG ratio of 1.1, promoted the formation of aggregates (hard clusters) after 1 hour under stirring. A GTA concentration between 1 and $24 \mathrm{M}$ was able to produce microparticles by complex coacervation and a hard shell around the particles was obtained which survived washing with hot water and no modification on the shell could be noticed. The increase of GA in the continuous phase decreased the time needed to form the solid shell down to few hours.

The stirring speed also influenced the cross linking reaction of GTA with the FG/GA complex coacervates. Low stirring speed $(200 \mathrm{rpm})$ resulted in large polynucleated capsules which contained numerous oil droplets. The complex coacervates were washed with water and when suspended in deionized water they remained in the form of polynucleated capsules. Consequently, the microcapsules aggregation can be controlled by having a certain minimum stirring speed during the reaction of FG/GA complex coacervates with GTA which can have an application if polynucleated microcapsules are wanted. Stirring speed of $370 \mathrm{rpm}$ gave single core microcapsules with a spherical shell (Figure 8a) and it was possible to produce single core microcapsules using higher rotation speed up to $550 \mathrm{rpm}$. The shell around the particles deformed under stirring at $550 \mathrm{rpm}$ (Figure 8b,c) but the oil drop within the solidified shell remained spherical (Figure 8d). Too high stirring speed (above $600 \mathrm{rpm}$ ) promoted aggregation and also numerous broken particles were observed.

\subsection{Effect of dispersed phase concentration in emulsion}


When the concentration of dispersed phase in the emulsion was increased from 10 to $30 \% \mathrm{v} / \mathrm{v}$ at FG:GA=50:50 and $\mathrm{BP}_{\mathrm{TOT}}=2 \% \mathrm{w} / \mathrm{w}$, the median particle diameter of emulsions was nearly constant $(\sim 88 \mu \mathrm{m})$ while the particle span slightly increased from 0.47 to 0.54 (Figure 9). However, beyond $30 \%$ of dispersed phase, as can be seen in Figure 9, the span was significantly increased up to 0.9 while the droplet size increased to $96 \mu \mathrm{m}$. It is possible that due to the increase in the oil concentration the number of produced droplets increased and there was not enough biopolymer present in the aqueous solution to completely cover the surface of the droplets.

\subsection{Effect of surface shear stress}

Figure 10 demonstrates the dependence of the median particle diameter and particle size distribution (span) with shear stress for $10 \% \mathrm{w} / \mathrm{w}$ sunflower oil in water emulsions prepared at FG:GA $=50: 50$ and $\mathrm{BP}_{\mathrm{TOT}}=2 \%$ w/w. As found earlier (Kosvintsev et al., 2005; Gasparini et al., 2008; Dragosavac et al., 2011) the droplet size decreased with increasing the stirrer speed due to an increase in the shear applied on the membrane surface (Eq. 2) which contributes to the drag force acting on droplets (Eq. 1). The droplet size strongly decreased with increasing the stirrer speed up to $600 \mathrm{rpm}$ corresponding to maximal shear stress at the membrane surface of $4 \mathrm{~Pa}$. At stirrer speeds above $1000 \mathrm{rpm}$, the median drop size was virtually independent on the stirrer speed and more than 3 times smaller than that at $170 \mathrm{rpm}$.

\subsection{Scale-up of FG/GA complex coacervation by pulsed flow ME}

Due to the great potential of microcapsules in applications for both food and pharmaceutical industries, scaling up of the system to higher throughputs was considered. A stirred cell cannot be easily scaled and therefore, pulsed flow membrane emulsification was used to scale-up the FG/GA complex coacervation. The main advantage of pulsed flow membrane emulsification is the continuous production with the ability to produce high disperse phase concentrations in a single pass of the continuous phase over the membrane surface: i.e. without the need for recirculation of the continuous phase. Figure 10 shows the effect of shear stress on the median particle diameter and particle size distribution in pulsed flow ME. The drop size decreased from 242 to $46 \mu \mathrm{m}$ as the shear stress increased from 1.3 to $13 \mathrm{~Pa}$. The droplet size is a strong function of shear stress up to $6 \mathrm{~Pa}$ but less so at a shear stress 
value between 6 and 13. At the shear stress of $13 \mathrm{~Pa}$ the particle size was 4.6 times the pore diameter. The data illustrates that approximately the same median particle size was obtained in the same range of shear stress using the Dispersion Cell and the pulsed flow membrane emulsification, confirming that at the low transmembrane flux it is the shear on the membrane surface that governs the droplet size. Decreasing the interfacial tension (according to Eq. 1) it would be possible to produce even smaller droplets.

Figure 11 illustrates the effect of the dispersed phase injection rates between 3.6 and $9.7 \mathrm{~mL}$ $\min ^{-1}$. This generated emulsions with a dispersed phase volume concentration of between 12 and $32 \% \mathrm{v} / \mathrm{v}$, in a single pass in terms of continuous phase cross-flow over the membrane surface. The droplet size increased from 79 to $111 \mu \mathrm{m}$ while the span was between 0.46 and 0.7. The droplet size increase with dispersed phase flux can be explained considering that the increase of dispersed phase flux results in an increase in the volume of oil flowing through the membrane pores during the detachment process, and the formation of larger droplets (Xu et al., 2005). In addition, when the dispersed phase flux is increased, the drop grows faster and larger droplets are generated as a consequence of the lower concentration of the polymers at the interface in the growth phase (Schröder et al., 1998; Geerken et al., 2007). Figure 11 shows that uniformly sized drops with a span value less than 0.5 were obtained at oil flow rate of $5.6 \mathrm{~mL} \mathrm{~min}^{-1}$ (corresponding to transmembrane flux $131 \mathrm{~L} \mathrm{~m}^{-2} \mathrm{~h}^{-1}$ ) and dispersed phase concentration of $19 \% \mathrm{v} / \mathrm{v}$ in a single pass. A span of 0.7 was obtained at high flow rate $\left(9.7 \mathrm{~mL} \mathrm{~min}^{-1}\right)$ and oil concentration $(32 \% \mathrm{v} / \mathrm{v})$ where low amount of biopolymer was available in the aqueous solution to completely cover all of the oil droplets surface that were quickly generated at the membrane pore interface.

\section{Conclusions}

Complex coacervate microcapsules with a single liquid core were produced using different weight ratios of FG to GA from 40:60 to 80:20 as a consequence of the attraction between oppositely charged biopolymers. Only the mixtures with the total biopolymer concentration lower than $4 \% \mathrm{w} / \mathrm{w}$ were able to undergo the separation of the initial solution and phase separation transition that determines the formation of the coating of the liquid coacervate phase around the oil droplets. Glutaraldehyde (GTA) was used to crosslink the shell formed around the oil droplets to form solid particles. A minimum concentration of GTA of $1.4 \mathrm{M}$ was necessary to promote the effective cross-linking reaction between FG and GTA and the 
optimal GTA concentration was $24 \mathrm{M}$. Microcapsule agglomeration was observed when too low (below $200 \mathrm{rpm}$ ) and too high (above $600 \mathrm{rpm}$ ) stirring speed was used. Production of oil droplets encapsulated in a biopolymer shell by complex coacervation was successful at various production scales: batch stirred cell membrane emulsification in a Dispersion Cell and continuous pulsed flow membrane emulsification. Using a $10 \mu \mathrm{m}$ pore sized sieve type membrane it was possible to generate droplets with a controllable median droplet size between 40 and $240 \mu \mathrm{m}$, with span values of significantly less than unity, and a value of $\sim 0.46$ at best in the range of shear stress between 1.3 and $24 \mathrm{~Pa}$. Using very low amounts of anionic emulsifier (SDS) it was possible to produce even smaller droplets due to the decrease of interfacial tension in the continuous phase. The correlation between droplet size and shear stress appeared to provide a reasonable fit with the data obtained with both the Dispersion Cell and the pulsed flow. The pulsed flow permits formation of emulsion in a continuous way and allows the production of FG/GA complex coacervate microcapsules at large scale under conditions of room temperature, at a considerable energy saving when compared to alternative gelatine types and production techniques.

The FG/GA system has many advantages including time and energy consumption reduction and increased consumer consent for religious or diet reasons and health safety. The results showed that the method proposed in the present work can be successfully applied for encapsulation purposes to produce microcapsules with controlled particle size and size distribution at production scale with low energy consumption (without significant temperature control) and using mild shear stress conditions compared to conventional methods used. Future work will be focused on microencapsulation of shear sensitive compounds using complex coacervation and membrane emulsification, applying the formulation and techniques described above.

\section{Acknowledgements}

This work was partially supported by "POR Calabria FSE 2007/2013- Asse IV - Obiettivo operativo M2" (postdoctoral fellowship). 


\section{References}

Alvim, I. D., \& Grosso, C. R. F. (2010). Microparticles obtained by complex coacervation: influence of the type of reticulation and the drying process on the release of the core material. Ciência e Tecnologia de Alimentos, 30, 1069-1076.

Atmane, M., Jacquot, M., Scher, J., \& Desobry, S. (2005). Flavour encapsulation and controlled release-a review. International Journal of Food Science \& Technology, 41, 1-21.

Benita, S. (2005). Microencapsulation: Methods and Industrial Applications. (2td ed.). London: Taylor \& Francis.

Bhattacharyya, A., \& Argillier, J. F. (2005). Micro-encapsulation by complex coacervation: influence of cationic surfactants. Journal of Surface Science and Technology, 21, 161-168.

Burgess, D. J., \& Ponsart, S. (1998). $\beta$-Glucuronidase activity following complex coacervation and spray drying microencapsulation. Journal of Microencapsulation, 15, 569579.

Bungenberg de Jong, H. G. (1949). Complex colloid systems. Colloid Science, 2, 335-432.

Chu, L., Park, S., Yamaguchi, T., \& Nakao S. (2002). Preparation of micron-sized monodispersed thermoresponsive core-shell microcapsules. Langmuir, 18, 1856-1864.

de Kruif, C. G., Weinbreck, F., \& de Vries, R. (2004). Complex coacervation of proteins and anionic polysaccharides. Current Opinion in Colloid \& Interface Science, 9, 340-349.

Dickinson, E., \& Lopez, G. (2001). Comparison of the emulsifying properties of fish gelatin and commercial milk proteins. Journal of Food Science, 66, 118-123.

Dragosavac, M. M., Vladisavljević, G. T., Holdich, R. G., \& Stillwell, M. T. (2011).

Production of porous silica microparticles by membrane emulsification. Langmuir, 28, 134143.

Dardelle, G., \&, V. Normand, V., (2012) Method for preparing microcapsules by coacervation. Patent US8,088,403 B2. 
Gasparini, G., Kosvintsev, S. R., Stillwell, M. T., \&, Holdich, R.G. (2008). Preparation and characterization of PLGA particles for subcutaneous controlled drug release by membrane emulsification. Colloids and Surfaces B: Biointerfaces, 61, 199-207.

Geerken, M. J., Lammertink, R. G. H., \& Wessling, M. (2007). Interfacial aspects of water drop formation at micro-engineered orifices. Journal of Colloid and Interface Science, 312, $460-469$.

Green, B. K.,\& Schleicher, L. (1957). Oil-containing microscopic capsules and method of making them. U.S. Patent 2,800,457.

Hermanson, G. T. (1996). Bioconjugate techniques. Academic press.

Holdich, R. G., Dragosavac, M. M, Vladisavljević, G. T., \& and Piacentini, E. (2013). Continuous Membrane Emulsification with Pulsed (Oscillatory) Flow, Industrial \& Engineering Chemistry Research, 52, 507-515.

Jie, Q., Kim, S. M., Pan, C.H., \& Chung, D. (2012). Characterization of fucoxanthin-loaded microspheres composed of cetyl palmitate-based solid lipid core and fish gelatin-gum arabic coacervate shell. Food Research International, 50, 31-37.

Jizomoto, H., Kanaoka, E., Sugita, K., \& Hirano, K. (1993). Gelatin-acacia microcapsules for trapping micro oil droplets containing lipophilic drugs and ready disintegration in the gastrointestinal tract. Pharmaceutical Research,, 10, 1115-1122.

Junyaprasert, V. B., Mitrevej, A., Sinchaipanid, N., Boonme, P., \& Wurster, D. E. (2001). Effect of process variables on the microencapsulation of vitamin A palmitate by gelatinacacia coacervation. Drug Development and Industrial Pharmacy, 27, 561-566.

Nakagawa, K., Iwamoto, S., Nakajima, M., Shono, A., \& Satoh, K. (2004). Microchannel emulsification using gelatin and surfactant-free coacervate microencapsulation, Journal of Colloid and Interface Science, 278, 198-205.

Karim, A. A., \& Bhat, R. (2009). Fish gelatin: properties, challenges, and prospects as an alternative to mammalian gelatins, Food Hydrocolloids, 23, 563-576.

Kosvintsev, S. R., Gasparini, G., Holdich, R. G., Cumming, I. W., \& Stillwell, M. T. (2005). Liquid-liquid membrane dispersion in a stirred cell with and without controlled shear. Industrial \& Engineering Chemistry Research, 44, 9323-9330. 
Kukizaki, M., \& Goto, M.. (2007). Preparation and evaluation of uniformly sized solid lipid microcapsules using membrane emulsification. Colloids and Surfaces A: Physicochemical and Engineering Aspects, 293, 87-94.

Leclercq, S., Harlander, K. R., \& Reineccius, G. A. (2009). Formation and characterization of microcapsules by complex coacervation with liquid or solid aroma cores. Flavour and Fragrance Journal, 24, 17-24.

Mayya, K. S., Bhattacharyya, A., \& Argillier, J. F. (2003). Micro-encapsulation by complex coacervation: influence of surfactant. Polymer International, 52, 644-647.

Migneault, I., Dartiguenave, C., Bertrand, M. J., \& Waldron, K. C. (2004). Glutaraldehyde: behavior in aqueous solution, reaction with proteins, and application to enzyme crosslinking. BioTechniques, 37, 790-806.

Priftis, D., \& Tirrell, M. (2012). Phase behaviour and complex coacervation of aqueous polypeptide solutions. Soft Matter, 8, 9396-9405.

Overbeek J.T.G., \& Voorn M.J. (1957). Phase separation in polyelectrolyte solutions. Theory of complex coacervation. Journal of Cellular and Comparative Physiology 49, 7-26.

Schmitt, C., Sanchez, C., Desobry-Banon, S., \& Hardy J. Schmitt, C. et al. (1998). Structure and technofuntional properties of protein-polysaccharide complexes: a review. Critical Reviews in Food Science and Nutrition, 38, 689-753.

Schröder, V., Behrend, O., \& Schubert, H. (1998). Effect of dynamic interfacial tension on the emulsification process using microporous, ceramic membranes. Journal of Colloid and Interface Science, 202, 334-340.

Soper, J. C. (1997). Method of encapsulating food or flavour particles using warm water fish gelatin, and capsules produced therefrom. U.S. Patent 5,603,952.

Surh, J., Decker, E. A., \& McClements, D. J. (2006). Properties and stability of oil-in-water emulsions stabilized by fish gelatin. Food Hydrocolloids, 20, 596-606.

Turgeon, S. L., Schmitt, C., \& Sanchez, C. (2007). Protein-polysaccharide complexes and coacervates. Current Opinion in Colloid \& Interface Science, 12, 166-178. 
Veis, A. (1964). The Macromolecular Chemistry of Gelatin. New York: Academic Press.

Vladisavljević, G. T., \& Williams, R. A. (2005). Recent developments in manufacturing emulsions and particulate products using membranes. Advances in Colloid and Interface Science, 113, 1-20.

Wampler, D. J. Soper, J. C., \& Pearl, T. T. (1998). Method of flavouring and mechanically processing foods with polymer encapsulated flavour oils. U.S. Patent 5,759,599.

Weinbreck, F., de Vries, R., Schrooyen, P., \& de Kruif, C. G. (2003). Complex coacervation of whey protein and gum arabic. Biomacromolecules, 4, 293-303.

Wie, W., Yuan, L., Hu, G., Wang, L. Y., Wu, J., Hu, X., Su, Z.G., \& Ma, G. H. (2008). Monodisperse chitosan microspheres with interesting structures for protein drug delivery. Advanced Materials, 20, 2292-2296.

Xu, J. H., Luo, G. S., Chen, G. G., \& Wang, J. D. (2005). Experimental and theoretical approaches on droplet formation from a micrometer screen hole. Journal of Membrane Science, 266, 121-131.

Yang, Y., Anvari, M., Pan, C. H., \& Chung, D. (2012). Characterization of interactions between fish gelatin and gum arabic in aqueous solutions. Food Chemistry, 135, 555-561.

Yeo, Y., Bellas, E., Firestone, W., Langer, R., \& Kohane, D. S. (2005). Complex coacervates for thermally sensitive controlled release of flavour compounds. Journal of Agricultural and Food Chemistry, 533, 7518-7525.

Zhou, Q. Z., Wang, L.Y., Ma, G.H., \& Su, Z. G., (2007). Preparation of uniform-sized agarose beads by microporous membrane emulsification technique. Journal of Colloid and Interface Science, 311, 118-127 


\section{List of Figures}

Figure 1 (a) Illustration of experimental equipment for the generation of liquid drops using Dispersion Cell with the simple paddle used $(b=12 \mathrm{~mm}, D=32 \mathrm{~mm}$, $D_{m}=33 \mathrm{~mm}, n_{b}=2$, and $T=40 \mathrm{~mm}$ ).

(b) Illustration of experimental equipment for the generation of liquid drops using continuous pulsed phase flow. The membrane used had a pore size $\left(d_{p}\right)$ of $10 \mu \mathrm{m}$ and pore spacing $(x)$ of $200 \mu \mathrm{m}$.

Figure 2 (a) Median particle diameter. (b) Span of particle size distributions of emulsions prepared using fish gelatine (FG) and/or gum arabic (GA) in the continuous phase.

Dispersed phase flow rate $=1 \mathrm{~mL} \min ^{-1}$; rotational speed $=630 \mathrm{rpm}$; Dispersed phase concentration $=10 \% \mathrm{v} / \mathrm{v}$. Room temperature, $\mathrm{pH}=5.4 \pm 0.2$.

Figure 3 (a) Median particle diameter. (b) Span of particle size distributions vs. FG:GA $(\mathrm{w} / \mathrm{w})$ in the aqueous biopolymer mixtures.

Dispersed phase flow rate $=1 \mathrm{~mL} \mathrm{m^{-1 }}$; rotational speed $=630 \mathrm{rpm}$; Dispersed phase concentration $=10 \% \mathrm{v} / \mathrm{v}$; Total biopolymer concentration $=$ $2 \% \mathrm{w} / \mathrm{w}$.

Figure 4 Microscope images of microcapsules crosslinked with glutaraldehyde and washed with hot water. Microcapsules produced using different ratios of FG:GA (a) 30:70; (b) 40:60; (c) 80:20; and (d) 50:50. Small dots in the background result from non-bonded polymer.

Dispersed phase flow rate $=1 \mathrm{~mL} \mathrm{~min}^{-1}$; rotational speed $=630 \mathrm{rpm} ; 10 \%$ $\mathrm{O} / \mathrm{W}$ emulsion; total biopolymer concentration $=2 \% \mathrm{w} / \mathrm{w}$.

Figure 5 (a) Median particle diameter. (b) Span of particle size distributions vs. total biopolymer concentration $\left(\mathrm{BP}_{\mathrm{TOT}}\right)$ in the aqueous biopolymer mixtures. Dispersed phase flow rate $=1 \mathrm{~mL} \mathrm{~min}^{-1}$; rotational speed $=630 \mathrm{rpm}$; Dispersed phase concentration $=10 \% \mathrm{v} / \mathrm{v} ; \mathrm{FG}: \mathrm{GA}=50: 50 \mathrm{w} / \mathrm{w}$.

Figure 6 (a) Median particle diameter. (b) Span of particle size distributions: emulsions prepared with and without SDS in the aqueous biopolymer mixtures. Dispersed phase flow rate $=1 \mathrm{~mL} \mathrm{m^{-1 }}$; rotational speed $=630 \mathrm{rpm}$; Dispersed phase concentration $=10 \% \mathrm{v} / \mathrm{v} ;$ FG:GA $=50: 50 \mathrm{w} / \mathrm{w}$; Total biopolymer concentration $=2 \% \mathrm{w} / \mathrm{w}$

Figure 7 Deposition of the coacervates around the oil drop with time.

(a) 30 min after the $\mathrm{pH}$ adjustment - coacervation phase starts to build around the drops; (b) 60 min after the $\mathrm{pH}$ adjustment - droplet fully coated with thin layer of coacervate; (c) 180 min after the $\mathrm{pH}$ adjustment - coacervate phase 
around the drops is soft ('sticky' phase); (d) solid shell crosslinked with glutaraldehyde - microcapsules washed with warm water. Small dots in the background result from non-bonded polymer.

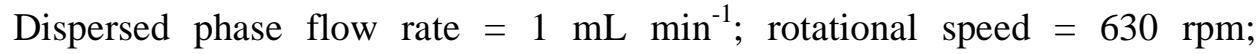
Dispersed phase concentration $=10 \% \mathrm{v} / \mathrm{v} ; \mathrm{FG}: \mathrm{GA}=50: 50 \mathrm{w} / \mathrm{w}, \mathrm{BP}_{\text {TOT }}=2 \%$ w/w.

Figure 8 Different shell shape due to the stirring during the solidification stage.

(a) Production conditions: dispersed phase flow rate $=1 \mathrm{ml} \mathrm{min}^{-1}$; shear stress = $24 \mathrm{~Pa}$, Stirring speed during the crosslinking $=370 \mathrm{rpm}$.

(b) Production conditions: dispersed phase flow rate $=1 \mathrm{ml} \mathrm{min}^{-1}$; shear stress = $11 \mathrm{~Pa}$; Stirring speed during the crosslinking $=550 \mathrm{rpm}$.

(c), (d) photographs of particles taken using confocal microscope to position the oil in elongated shell (production conditions same as (b)).

Figure 9 (a) Median particle diameter. (b) Span of particle size distributions vs. dispersed (oil) phase concentration .

Dispersed phase flow rate $=1 \mathrm{~mL} \mathrm{~min}^{-1}$; rotational speed $=630 \mathrm{rpm} ; \mathrm{FG}: \mathrm{GA}=$ $50: 50 \mathrm{w} / \mathrm{w}$; Total biopolymer concentration $=2 \% \mathrm{w} / \mathrm{w}$

Figure 10 (a) Median particle diameter. (b) Span of particle size distributions vs. shear stress using Dispersion cell and Pulsed Flow continuous phase system.

Dispersed phase flow rate $=1 \mathrm{~mL} \mathrm{~min}^{-1}$; Dispersed phase concentration $=10 \%$ $\mathrm{w} / \mathrm{w} ; \mathrm{FG}: \mathrm{GA}=50: 50 \mathrm{w} / \mathrm{w}$; Total biopolymer concentration $=2 \% \mathrm{w} / \mathrm{w}$

Figure 11 (a) Median particle diameter. (b) Span of particle size distributions vs. dispersed phase injection rate using the pulsed flow continuous phase system. $\%$ $\mathrm{v} / \mathrm{v}$ correspond to the final oil content in the emulsion.

Amplitude pulse $=1.6 \mathrm{~mm}$; Frequency $=30 \mathrm{~Hz} ;$ FG:GA $=50: 50 \mathrm{w} / \mathrm{w}$; Total biopolymer concentration $=2 \% \mathrm{w} / \mathrm{w}$. 
(a)

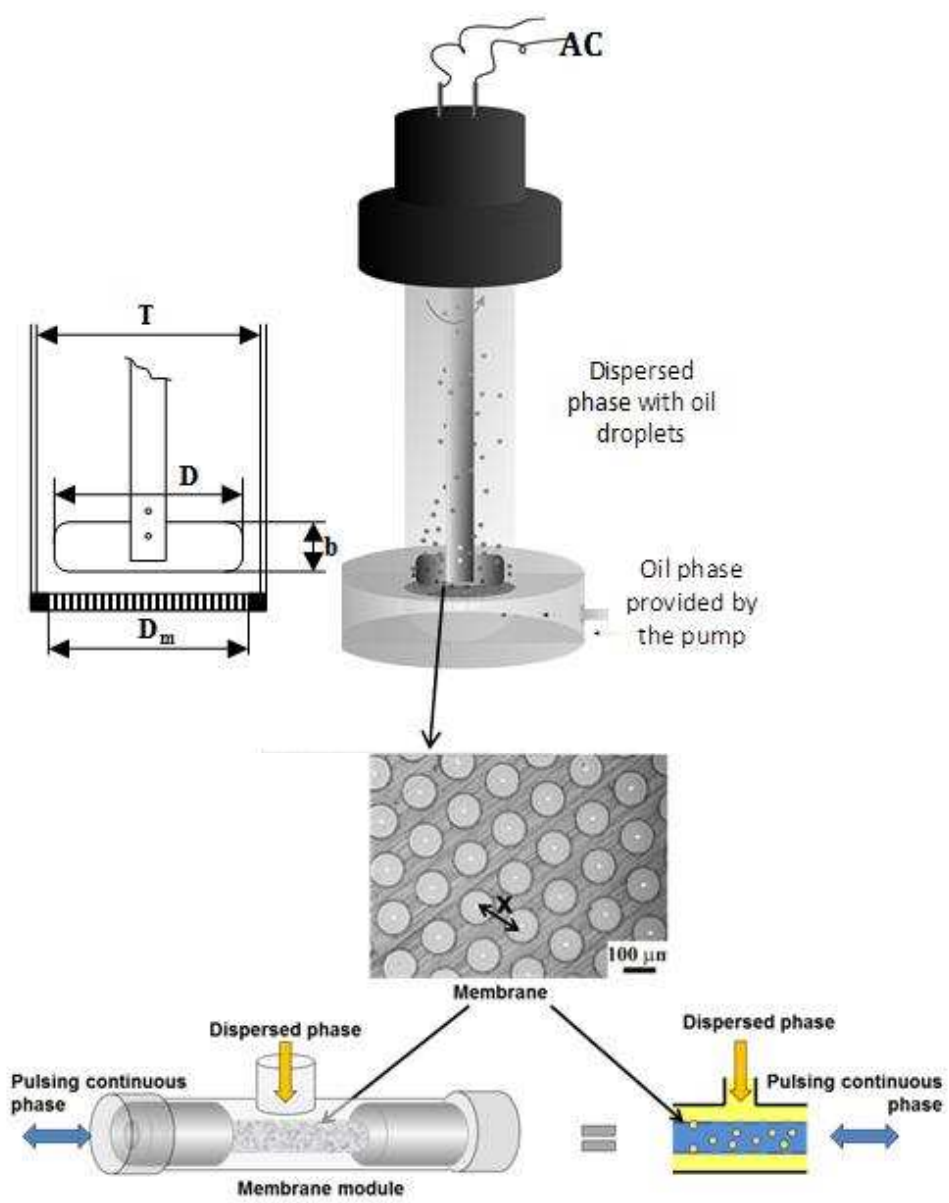

(b)
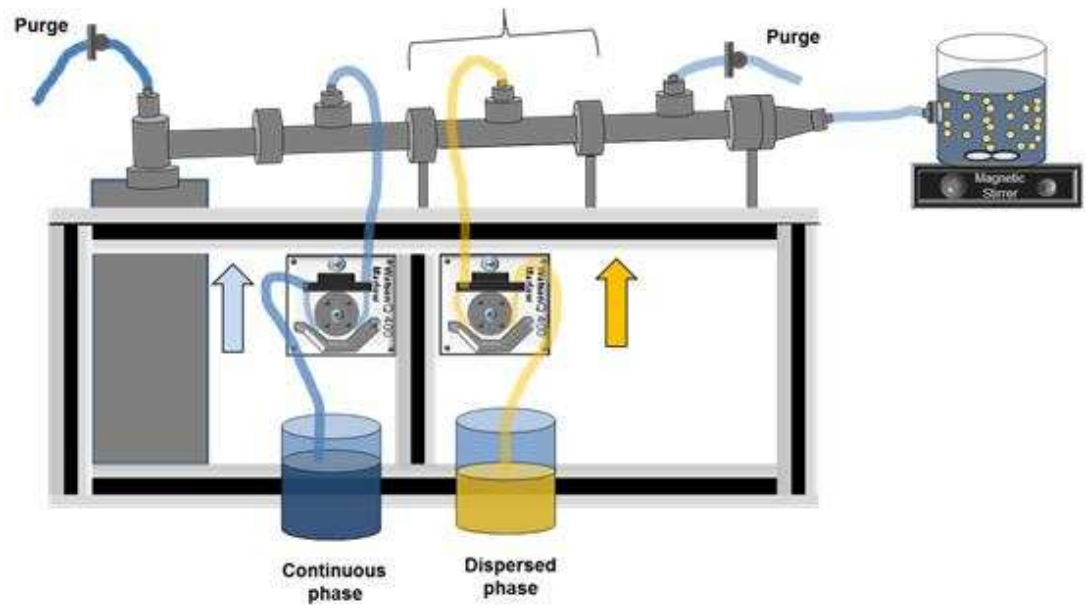

Figure 1 (a) Illustration of experimental equipment for the generation of liquid drops using Dispersion Cell with the simple paddle used $(b=12 \mathrm{~mm}, D=32 \mathrm{~mm}$, $D_{m}=33 \mathrm{~mm}, n_{b}=2$, and $T=40 \mathrm{~mm}$ ). 
(b) Illustration of experimental equipment for the generation of liquid drops using continuous pulsed phase flow. The membrane used had a pore size $\left(d_{p}\right)$ of $10 \mu \mathrm{m}$ and pore spacing $(x)$ of $200 \mu \mathrm{m}$.
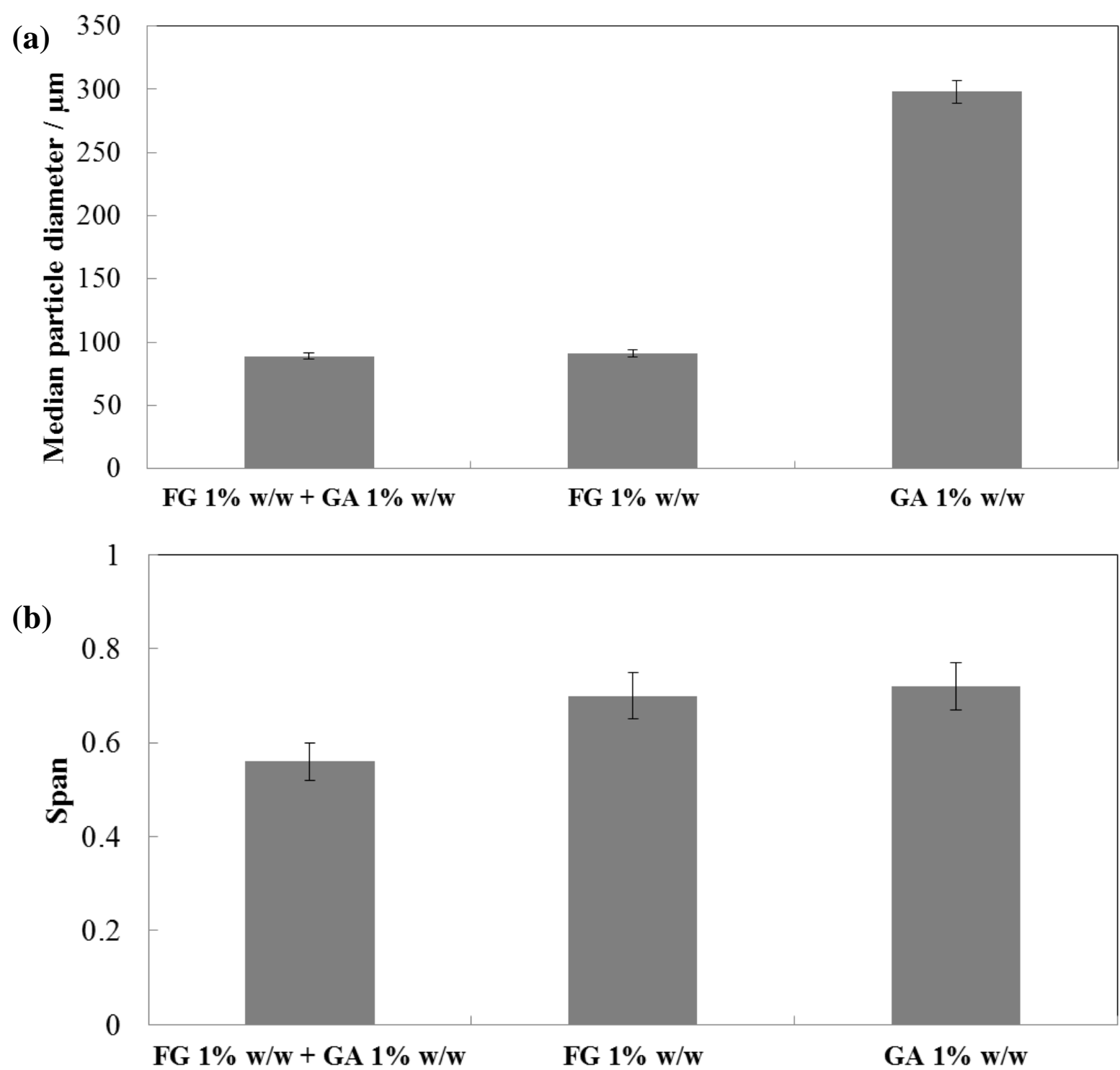

Figure 2 (a) Median particle diameter. (b) Span of particle size distributions of emulsions prepared using fish gelatine (FG) and/or gum arabic (GA) in the continuous phase.

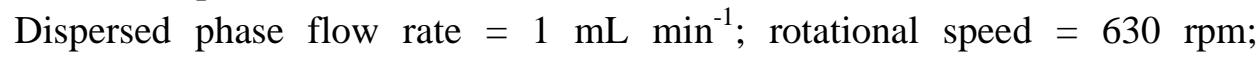
Dispersed phase concentration $=10 \% \mathrm{v} / \mathrm{v}$. Room temperature, $\mathrm{pH}=5.4 \pm 0.2$. 

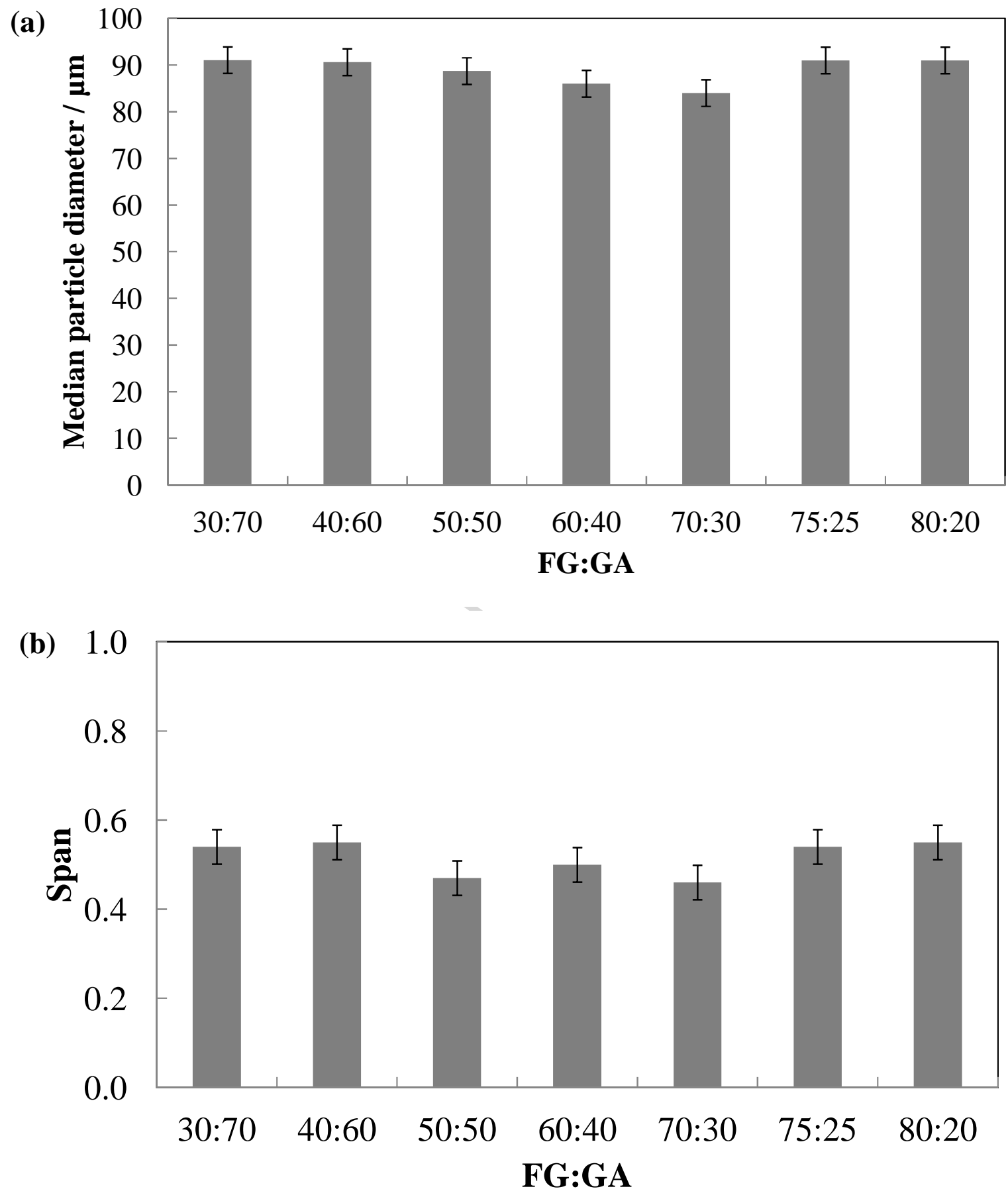

Figure 3 (a) Median particle diameter. (b) Span of particle size distributions vs. FG:GA $(\mathrm{w} / \mathrm{w})$ in the aqueous biopolymer mixtures.

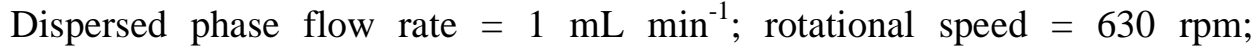
Dispersed phase concentration $=10 \% \mathrm{v} / \mathrm{v}$; Total biopolymer concentration $=$ $2 \% \mathrm{w} / \mathrm{w}$. 


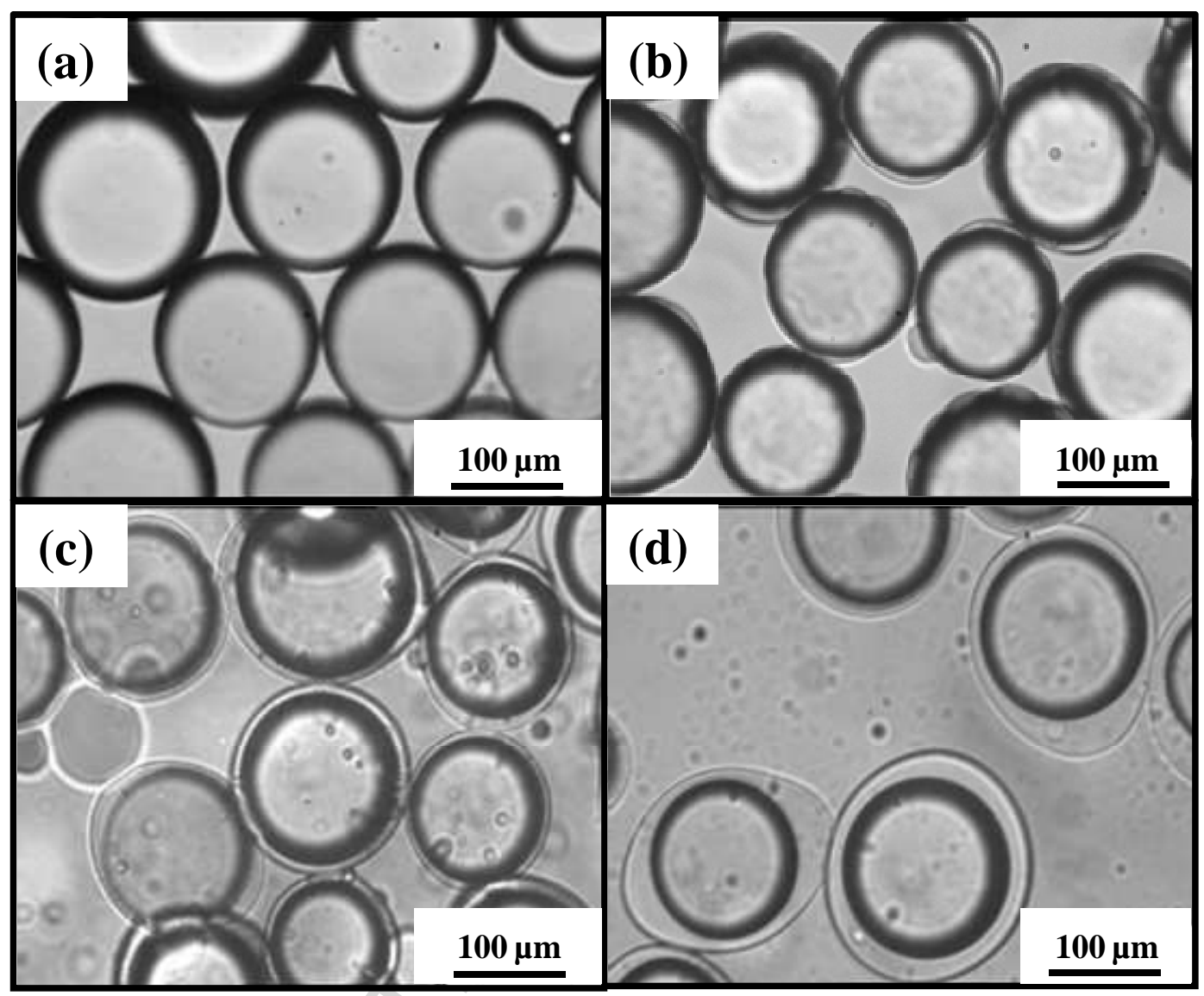

Figure 4 Microscope images of microcapsules crosslinked with glutaraldehyde and washed with hot water. Microcapsules produced using different ratios of FG:GA (a) 30:70; (b) 40:60; (c) 80:20; and (d) 50:50. Small dots in the background result from non-bonded polymer.

Dispersed phase flow rate $=1 \mathrm{~mL} \mathrm{~min}^{-1}$; rotational speed $=630 \mathrm{rpm} ; 10 \%$ $\mathrm{O} / \mathrm{W}$ emulsion; total biopolymer concentration $=2 \% \mathrm{w} / \mathrm{w}$. 


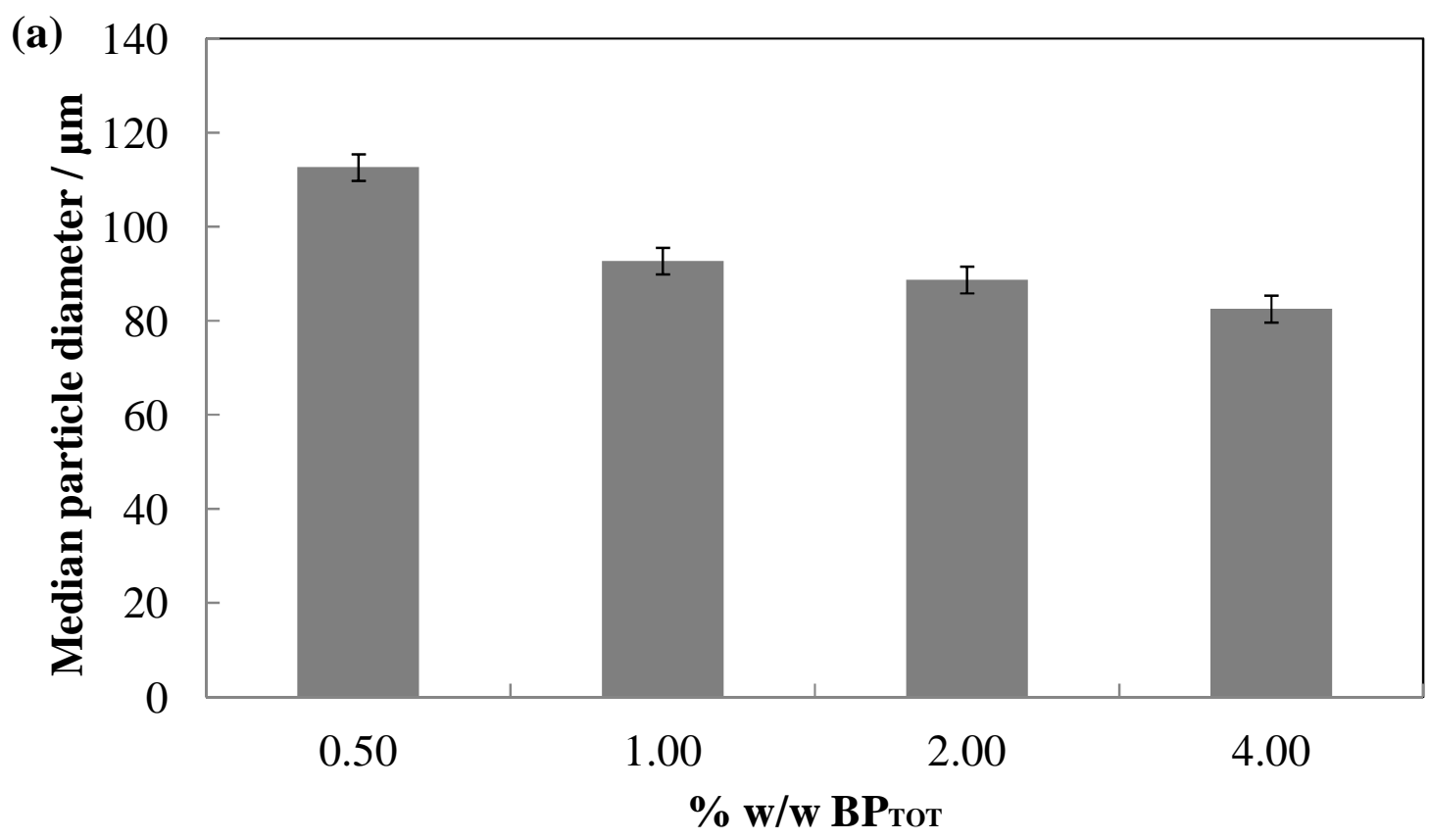

(b)

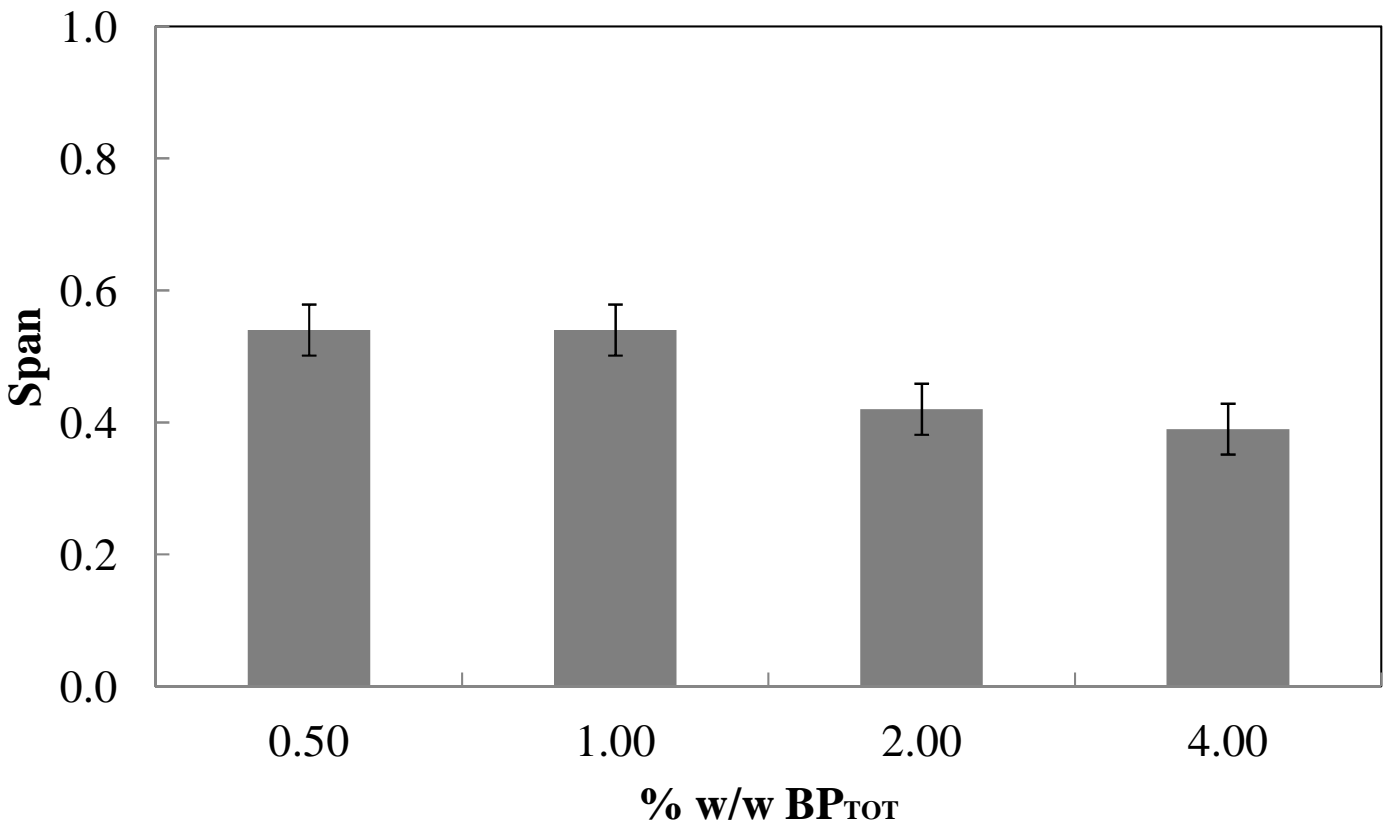

Figure 5 (a) Median particle diameter. (b) Span of particle size distributions vs. total biopolymer concentration $\left(\mathrm{BP}_{\mathrm{TOT}}\right)$ in the aqueous biopolymer mixtures. Dispersed phase flow rate $=1 \mathrm{~mL} \mathrm{~min}^{-1}$; rotational speed $=630 \mathrm{rpm}$; Dispersed phase concentration $=10 \% \mathrm{v} / \mathrm{v} ; \mathrm{FG}: \mathrm{GA}=50: 50 \mathrm{w} / \mathrm{w}$. 
(a)
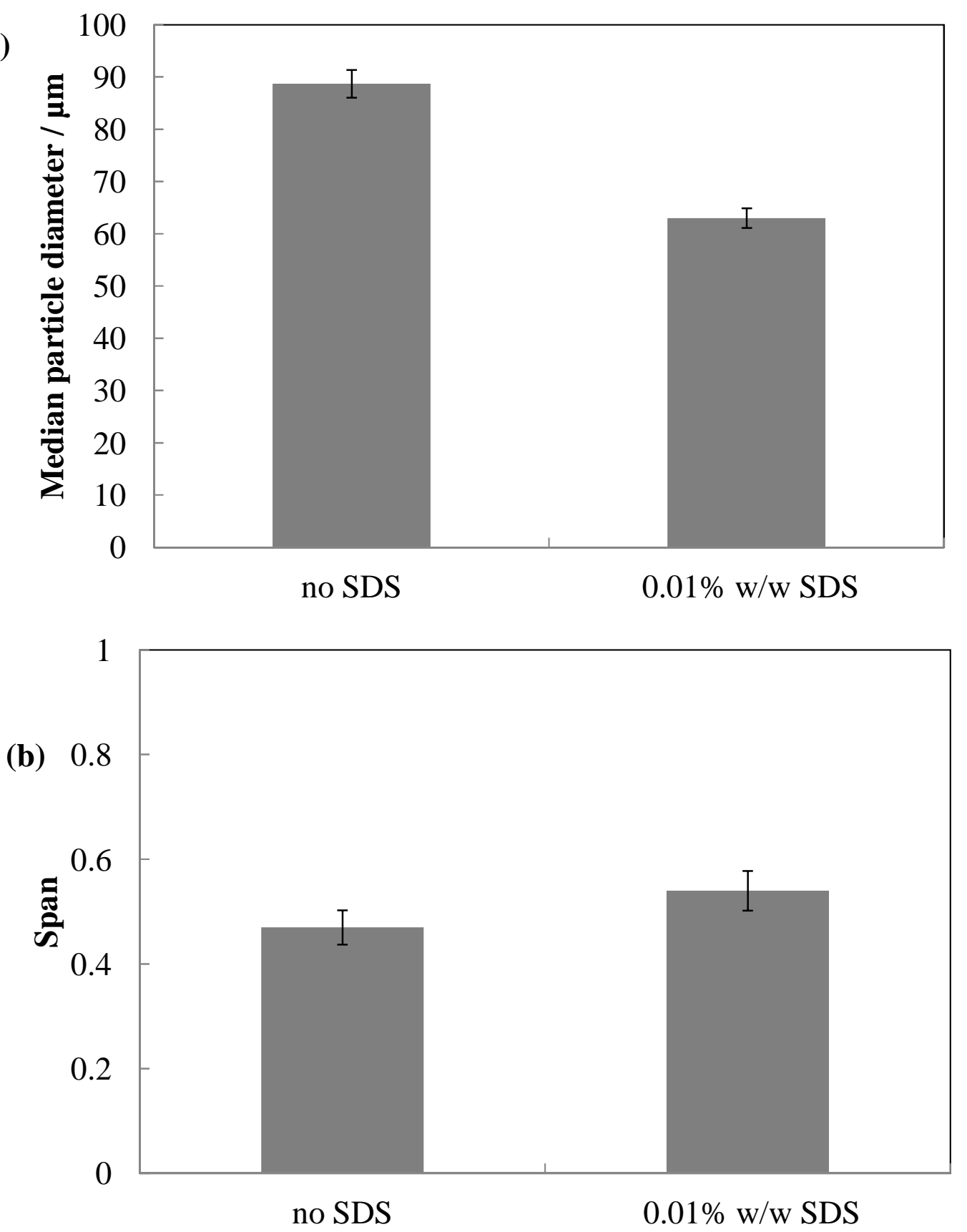

Figure 6 (a) Median particle diameter. (b) Span of particle size distributions: emulsions prepared with and without SDS in the aqueous biopolymer mixtures.

Dispersed phase flow rate $=1 \mathrm{~mL} \mathrm{m^{-1 }}$; rotational speed $=630 \mathrm{rpm}$; Dispersed phase concentration $=10 \% \mathrm{v} / \mathrm{v} ;$ FG:GA $=50: 50 \mathrm{w} / \mathrm{w}$; Total biopolymer concentration $=2 \% \mathrm{w} / \mathrm{w}$. 


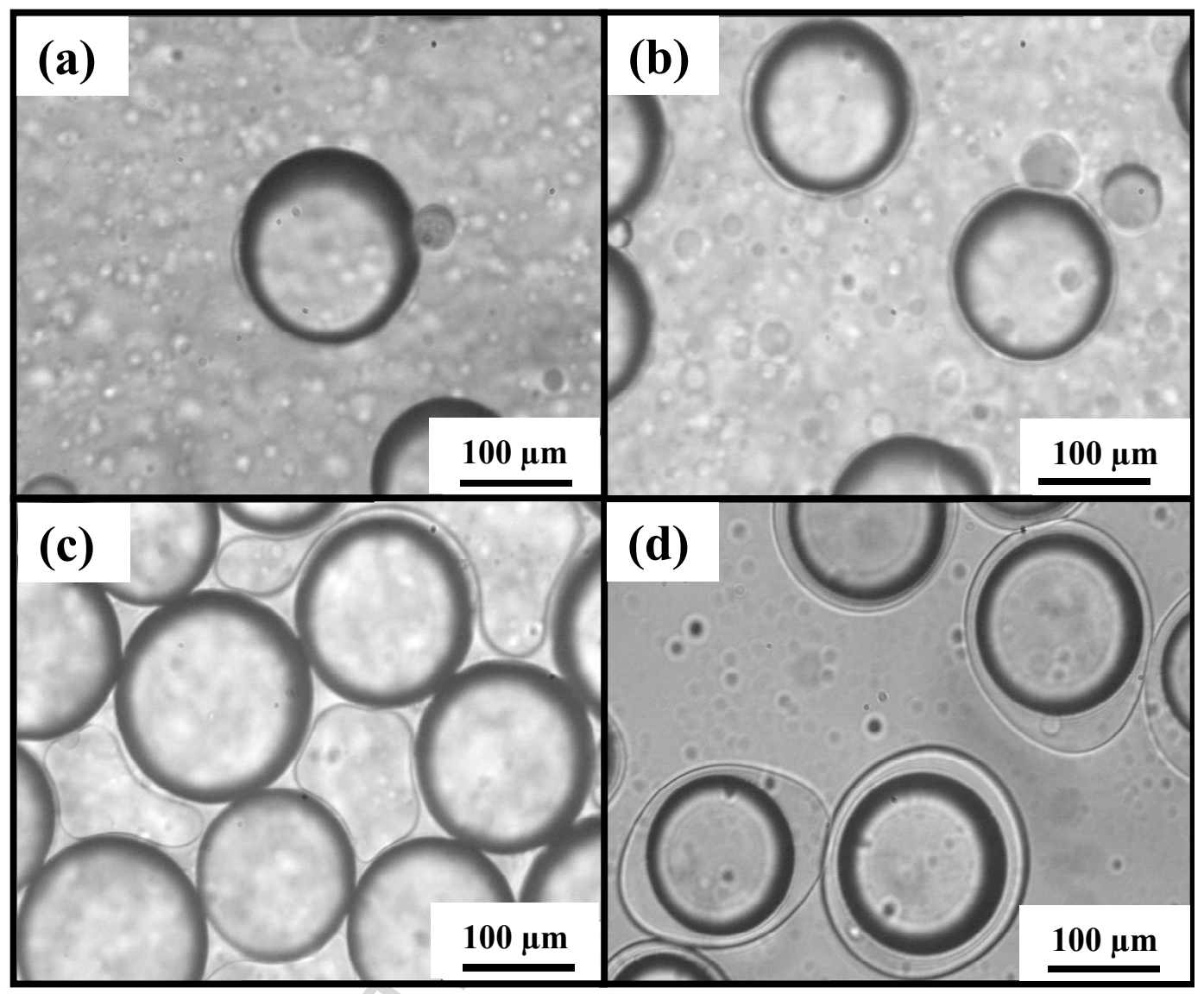

Figure 7 Deposition of the coacervates around the oil drop with time.

(a) 30 min after the $\mathrm{pH}$ adjustment - coacervation phase starts to build around the drops; (b) 60 min after the $\mathrm{pH}$ adjustment - droplet fully coated with thin layer of coacervate; (c) 180 min after the $\mathrm{pH}$ adjustment - coacervate phase around the drops is soft ('sticky' phase); (d) solid shell crosslinked with glutaraldehyde - microcapsules washed with warm water. Small dots in the background result from non-bonded polymer.

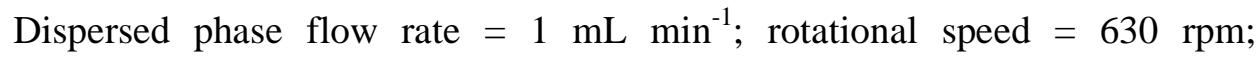
Dispersed phase concentration $=10 \% \mathrm{v} / \mathrm{v} ; \mathrm{FG}: \mathrm{GA}=50: 50 \mathrm{w} / \mathrm{w}, \mathrm{BP}_{\mathrm{TOT}}=2 \%$ w/w. 


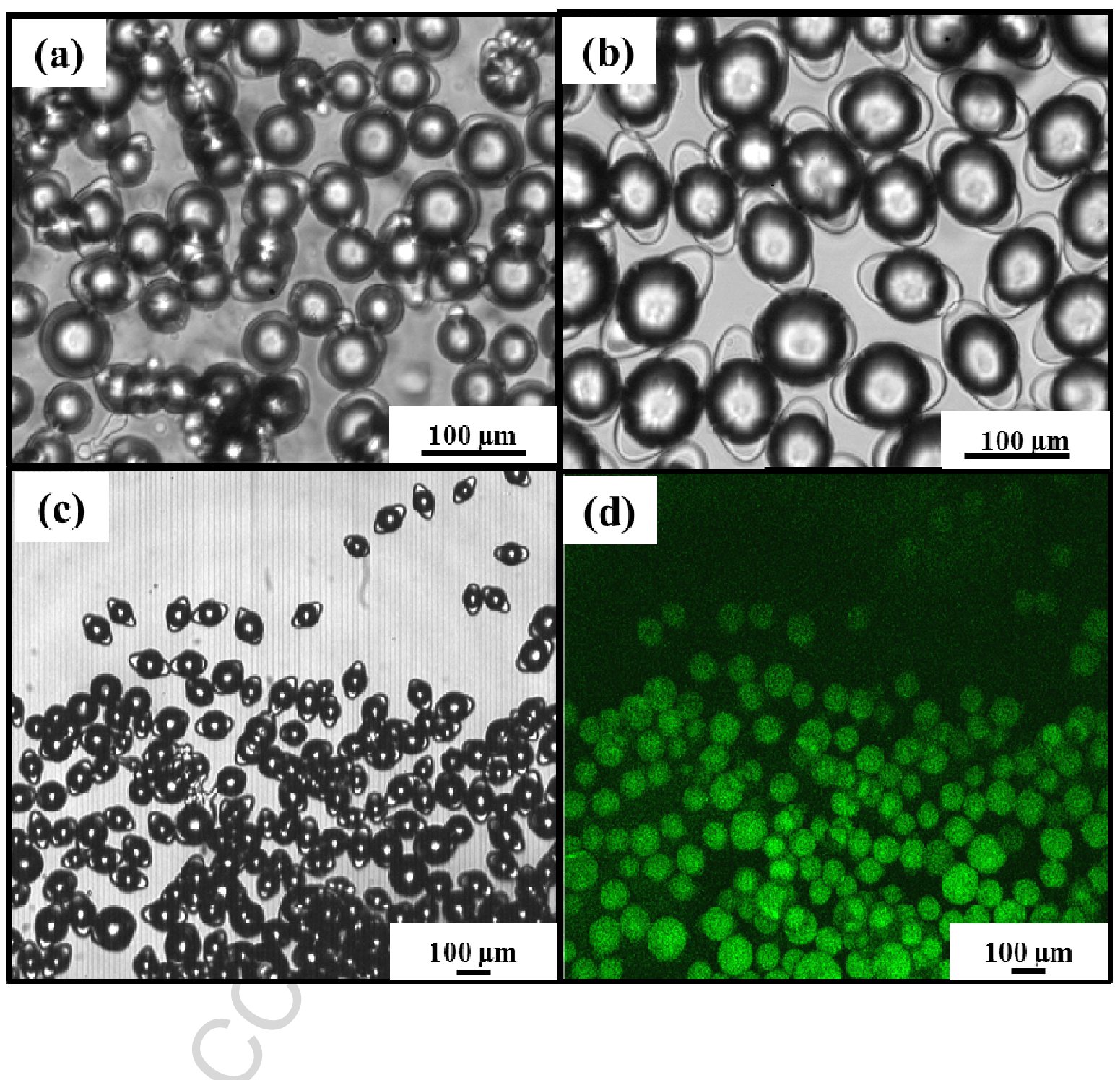

Figure 8 Different shell shape due to the stirring during the solidification stage.

(a) Production conditions: dispersed phase flow rate $=1 \mathrm{ml} \mathrm{min}^{-1}$; shear stress = $24 \mathrm{~Pa}$, Stirring speed during the crosslinking $=370 \mathrm{rpm}$.

(b) Production conditions: dispersed phase flow rate $=1 \mathrm{ml} \mathrm{min}^{-1}$; shear stress $=$ $11 \mathrm{~Pa}$; Stirring speed during the crosslinking $=550 \mathrm{rpm}$.

(c), (d) photographs of particles taken using confocal microscope to position the oil in elongated shell (production conditions same as (b)). 

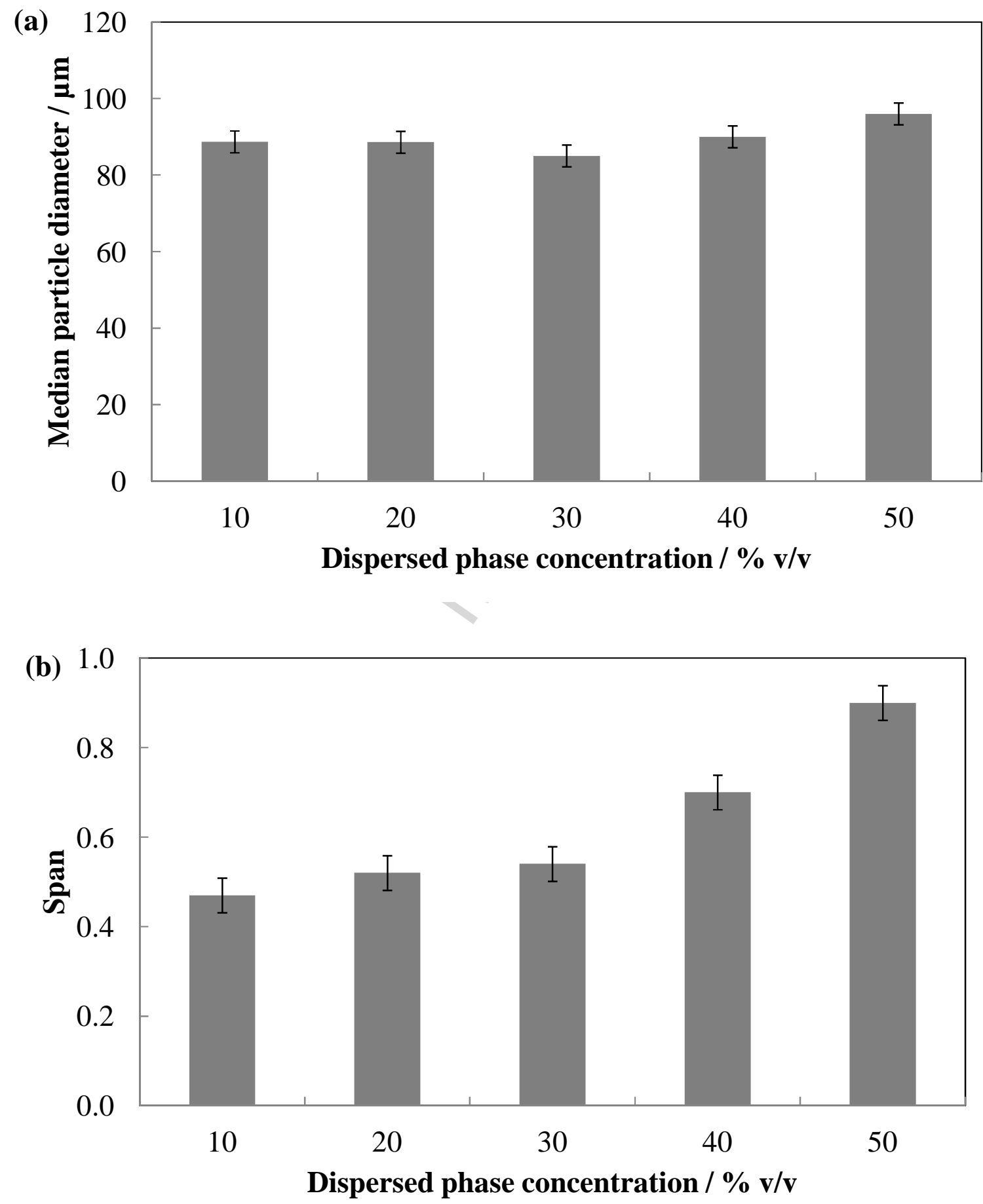

Figure 9 (a) Median particle diameter. (b) Span of particle size distributions vs. dispersed (oil) phase concentration .

Dispersed phase flow rate $=1 \mathrm{~mL} \mathrm{~min}^{-1}$; rotational speed $=630 \mathrm{rpm} ; \mathrm{FG}: \mathrm{GA}=$ $50: 50 \mathrm{w} / \mathrm{w}$; Total biopolymer concentration $=2 \% \mathrm{w} / \mathrm{w}$. 
(a)

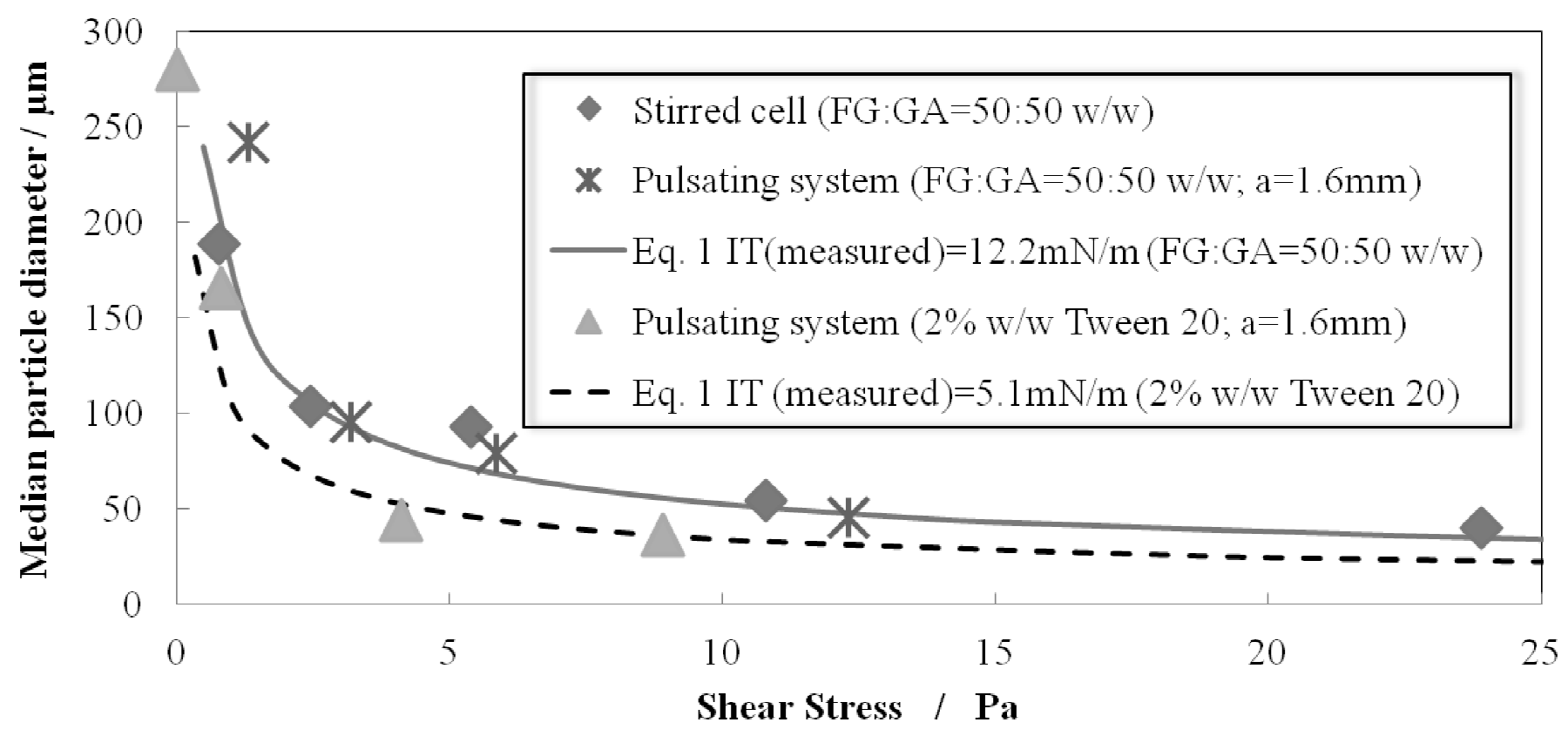


(b)

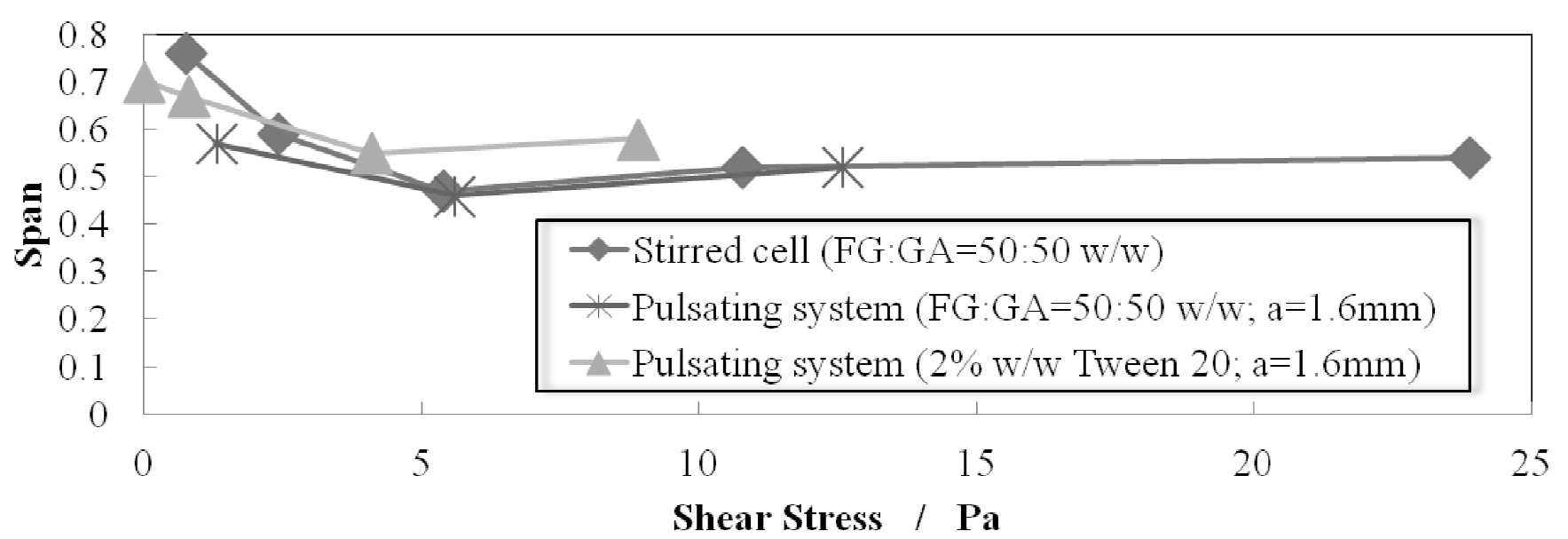

Figure 10 (a) Median particle diameter. (b) Span of particle size distributions vs. shear stress using Dispersion cell and Pulsed Flow continuous phase system.

Dispersed phase flow rate $=1 \mathrm{~mL} \mathrm{~min}^{-1}$; Dispersed phase concentration $=10 \% \mathrm{w} / \mathrm{w} ;$ FG:GA $=50: 50 \mathrm{w} / \mathrm{w}$; Total biopolymer concentration $=2 \% \mathrm{w} / \mathrm{w}$. 


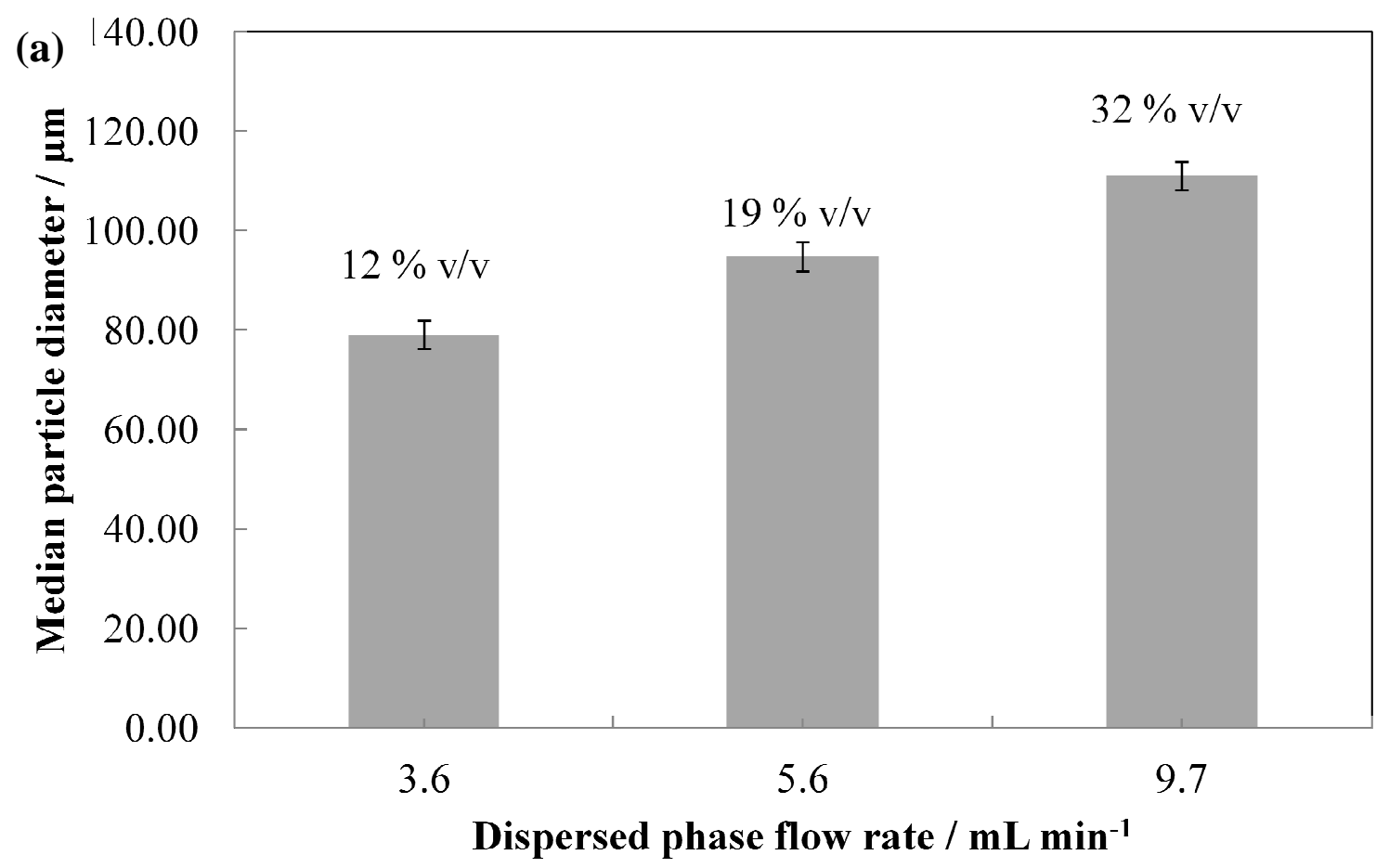

(b)

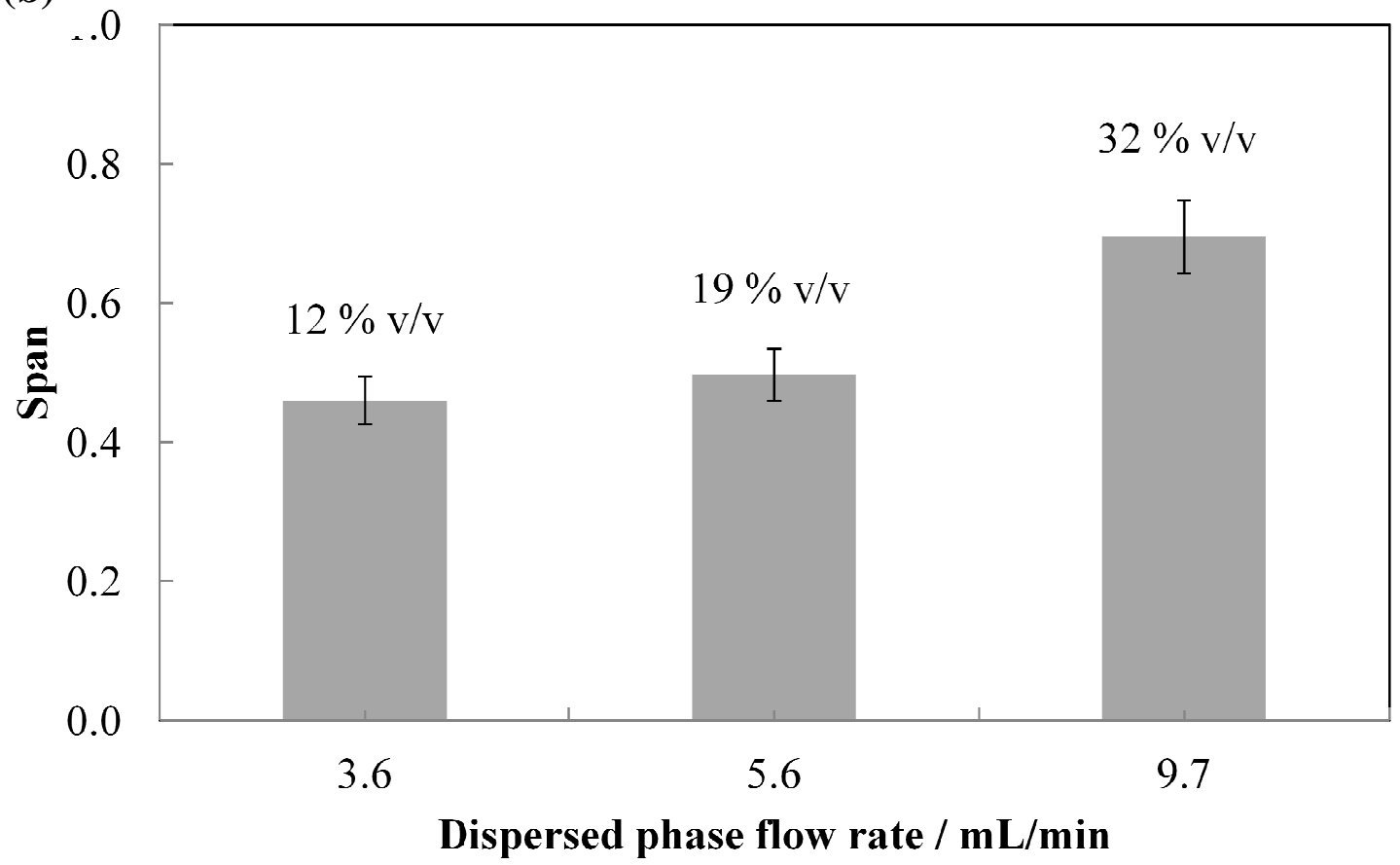

Figure 11 (a) Median particle diameter. (b) Span of particle size distributions vs. dispersed phase injection rate using the pulsed flow continuous phase system. \% $\mathrm{v} / \mathrm{v}$ correspond to the final oil content in the emulsion. 
Amplitude pulse $=1.6 \mathrm{~mm}$; Frequency $=30 \mathrm{~Hz} ;$ FG:GA $=50: 50 \mathrm{w} / \mathrm{w} ;$ Total biopolymer concentration $=2 \% \mathrm{w} / \mathrm{w}$. 
Table 1 Aqueous/oil interfacial tension at different weight ratios of biopolymers used for the preparation of microcapsules before and after $\mathrm{pH}$ adjustment.

FG -fish gelatine; GA - gum arabic

\begin{tabular}{|c|c|c|c|c|}
\hline \multicolumn{2}{|c|}{ Biopolymer } & \multirow{2}{*}{$\begin{array}{c}\text { Interfacial } \\
\text { tension } \\
\text { before pH } \\
\text { adjustment } \\
(\mathrm{pH}=5.4 \pm 0.2) \\
\left(\mathrm{mN} \mathrm{m^{-1 } )}\right. \\
\end{array}$} & \multirow{2}{*}{$\begin{array}{l}\text { Interfacial tension } \\
\text { after } \mathrm{pH} \text { adjustment } \\
\qquad\left(\mathrm{mN} \mathrm{m}^{-1}\right)\end{array}$} & \multirow{2}{*}{$\begin{array}{l}\text { pH of biopolymer } \\
\text { mixture adjusted } \\
\text { to promote } \\
\text { complex } \\
\text { coacervation }\end{array}$} \\
\hline FG:GA & $\begin{array}{l}\mathbf{B P}_{\mathrm{TO}} \\
\mathrm{T}(\% \\
\mathbf{w} / \mathbf{w})\end{array}$ & & & \\
\hline $0: 100$ & 1 & 16.8 & 16.8 & - \\
\hline 100:0 & 1 & 10.6 & 10.7 & - \\
\hline $50: 50$ & 0.5 & 14.9 & 15.0 & 3.5 \\
\hline $50: 50$ & 1 & 12.4 & 12.5 & 3.5 \\
\hline $50: 50$ & 2 & 12.2 & 12.4 & 3.5 \\
\hline $50: 50$ & 4 & 10.6 & 10.6 & 3.5 \\
\hline $80: 20$ & 2 & $12.3-$ & 12.4 & 4.5 \\
\hline $70: 30$ & 2 & 12.4 & 12.3 & 4.0 \\
\hline $60: 40$ & 2 & 12.3 & 12.4 & 4.0 \\
\hline $40: 60$ & 2 & 12.2 & 12.4 & 3.2 \\
\hline $30: 70$ & 2 & 12.2 & 12.3 & 2.7 \\
\hline $\begin{array}{c}50: 50 \\
+0.01 \% \\
\text { w/w SDS }\end{array}$ & 2 & 6.2 & 6.4 & 3.5 \\
\hline
\end{tabular}




\section{Highlights}

- Highly uniform complex coacervate microcapsules with a single liquid core were produced at room temperature

- Fish gelatin/gum arabic complex coacervate shell cross-linked by glutaraldehyde

- Continuous pulsed flow membrane emulsification was successfully used for scaling up and production of complex coacervate microcapsules 